\title{
Asset Pricing in Production Economies with Extrapolative Expectations*
}

\author{
David Hirshleifer Jianfeng $\mathrm{Yu}$
}

August 2012

\begin{abstract}
Introducing extrapolation bias into a standard one-sector production-based real business cycle model with recursive preferences reconciles salient stylized facts about business cycles (low consumption volatility and high investment volatility relative to output) and financial markets (high equity premium, volatile stock returns, and a low and smooth riskfree rate) with low relative risk aversion and an intertemporal elasticity of substitution in preferences of greater than one. Furthermore, the model matches several conditional stylized facts, such as return predictability based upon dividend yield, $Q$, and investment rates. These successes derive from the interaction of capital adjustment costs, extrapolative bias, and recursive preferences. Extrapolative bias increases the variation in the wealth-consumption ratio; recursive preferences cause this variation to be strongly priced; and adjustment costs decrease the covariance between marginal utility of consumption and asset returns. We provide empirical support for the mechanism of the model.
\end{abstract}

JEL Classification: G02, G12, G14, E30

Keywords: extrapolation, production-based model, long-run risk, recursive preferences

\footnotetext{
* We thank Frederico Belo, Jules Van Binsbergen, Scott Cederburg, Hui Chen, James Choi, Will Goetzmann, Francois Gourio, Alan Huang, Ralph Koijen, Chris Lamoureux, Lars Lochstoer, Sydney Ludvigson, Shaojin Li, Stavros Panageas, Neng Wang, Moto Yogo, Lu Zhang, and seminar participants at the University of Arizona, Peking University, University of California at Irvine, Yale University, 2011 Chicago Booth-Deutsche Bank Symposium, AFA 2012 Chicago Meeting, NBER 2011 Behavioral Economics Meeting, 22nd Conference in Financial Economics and Accounting, 3rd SUFE Conference on Capital Markets and Corporate Finance, 2012 China International Conference in Finance, and the 2011 Minnesota MacroFinance Conference for helpful comments. We also thank Jun Li for exceptional research assistance. Contact information: David Hirshleifer: The Paul Merage School of Business University of California, Irvine, CA 92697-3125. Email: david.h@uci.edu. Tel: (949) 724-2896. Jianfeng Yu: University of Minnesota, 321 19th Avenue South, Suite 3-122, Minneapolis, MN 55455. Email jianfeng@umn.edu, Phone: 612-625-5498, Fax: 612-626-1335.
} 


\section{Introduction}

During the millennial high tech boom, the U.S. economy grew rapidly, and expectations among many investors about future growth were higher than subsequent realizations. In contrast, after the credit crisis of 2008, growth has been low and pessimistic expectations for future growth have been prevalent. This raises the questions of whether there is a general tendency for individuals to overextrapolate recent economic growth, and if so what effect this has on consumption and asset pricing.

Evidence from both psychology and finance indicates that extrapolative bias is pervasive in human judgement and decisions (see, e.g., Hirshleifer (2001), Barberis and Thaler (2003), and Fuster, Laibson, and Mendel (2010)). In laboratory experiments, Tversky and Kahneman (1974) provide evidence consistent with individuals following the representativeness heuristic, wherein observations are perceived as being more indicative (representative) of population distributions than they really are. This results in the socalled 'law of small numbers', a belief updating process whereby individuals overweight small numbers of observations. In an investment setting, this would imply that when investors see a firm realizing high earnings growth, for example, they may classify it as a growth firm and discount inadequately for the regression phenomenon.

Empirically, several field and experimental studies find that the trading of individual and professional investors seems to reflect extrapolation of past performance. ${ }^{1}$ Theoretical models and discussions have also emphasized how extrapolation can affect capital market behavior. In the model of Barberis, Shleifer and Vishny (1998), the representativeness heuristic causes overreaction anomalies in the stock market. Fuster, Laibson, and Mendel (2010) suggest that extrapolation is important for understanding macroeconomic fluctuations. Indeed, Barberis (2011) proposes that overextrapolation may explain the 2008 credit crisis.

As is well known, production-based asset pricing models face an even greater challenge than endowment-based models in explaining consumption and asset return behavior, as such

\footnotetext{
${ }^{1}$ See, e.g., Smith, Suchanek, and Williams (1988), Benartzi (2001), Haruvy, Lahav, and Noussair (2007), Greenwood and Nagel (2009), Choi, Laibson and Madrian (2010). In survey evidence, Case and Shiller (1988) report higher expectations of future housing price growth in cities that have experienced past recent price growth. Using both survey and experimental data, De Bondt (1993) finds that the forecasts of individual investors satisfy a simple trend-following mechanism. Vissing-Jorgensen (2003) provides survey evidence that investors who have experienced high portfolio returns in the past expect higher returns in the future. Furthermore, Ederington and Golubeva (2010) find that mutual fund investors reallocate toward stock funds after stock price increases, and into bond funds after bond price increases.
} 
models allow greater scope for endogenous consumption and dividend smoothing (see, e.g., Rouwenhorst (1995), Jermann (1998), Lettau and Uhlig (2000), and Boldrin, Christiano, and Fisher (2001)). ${ }^{2}$ It has been recognized for some time that relaxing the assumption of perfect rationality might help explain macroeconomic and financial empirical puzzles. ${ }^{3}$ Recently, Fuster, Laibson, and Mendel (2010) and Fuster, Hebert, and Laibson (2011) argue that quasi-rational models deserve greater attention.

In this spirit, in this paper we introduce extrapolative expectations into a standard dynamic stochastic general equilibrium (DSGE) model featuring recursive preferences to study the implications of the model for asset prices, consumption, investment, and output. Specifically, we assume that the true average productivity growth is unobservable, and that the representative individual has to estimate it from historical data. The individual uses a smoothed average of past realized technology growth to estimate future technology growth, with greater weight on the most recent growth realization.

We show that introducing extrapolative expectations greatly improves upon traditional rational models in matching key stylized facts about both asset prices and macroeconomic quantities. Specifically, our model produces large and volatile excess stock market returns and low and smooth risk-free rates, with a relative risk aversion (RRA) of four and a preference intertemporal elasticity of substitution (IES) of two. Moreover, the model can replicate the predictability of excess market returns by the price-dividend ratio, Tobin's $Q$, and investment rates, consistent with known evidence. Importantly, extrapolative expectations also improves the model's ability to match the relative volatilities of investment growth.

The intuition for the high equity premium in our model is straightforward. First, extrapolation of past growth trends cause excess volatility in productivity growth expectations. This increases the volatility of investment, and since variations in investment are driven by excessive volatility in perceived productivity, this results in excessive perceived volatility of the consumption growth rate. Second, owing to recursive preferences, this variation in the perceived consumption growth rate (i.e., the long-run risk) is heavily priced.

Finally, with reasonably high adjustment costs, the limited flexibility of investment tends

\footnotetext{
${ }^{2}$ Several endowment-based asset-pricing models can successfully match the first two moments of the excess stock market return and the risk-free rate (e.g., Campbell and Cochrane (1999), Bansal and Yaron (2004), and Barro (2006)). However, the reconciliation of asset markets with aggregate quantities has proved to be a challenge for DSGE models.

${ }^{3}$ Early notable studies include De Long et al. (1990a, 1990b) and Barsky and De Long (1993).
} 
to direct the payoff from high realized TFP growth more towards dividends and consumption rather than investment. This reduces marginal utility of consumption in the event of a favorable TFP shock. Since the positive TFP shock is associated with a high asset return, higher adjustment costs tend to decrease the covariance between return and marginal utility of consumption, thereby increasing the equity risk premium. Thus, taken together, the combination of extrapolation bias, adjustment costs, and recursive preferences can generate a large equity premium.

All three of adjustment costs, extrapolation and recursive preferences contribute to this outcome. Without capital adjustment costs, consumption is excessively smoothed, because after high growth realizations, firms would heavily reinvest cash flows, reducing the payouts and consumption or making them countercyclical; this would reduce equity risk. Without extrapolation bias, the perceived volatility of investment and consumption growth would be too small to explain a high equity premium. Finally, without recursive preferences, the time-variation in perceived consumption growth is not priced, and thus the equity premium is small.

The intuition for conditional return predictability derives from extrapolative expectations and overreaction. By a standard argument, overreaction results in higher volatility in the stock market and the wealth-consumption ratio, and predictability of stock returns by valuation ratios and investment rates.

As observed by Barlevy (2004) and Lansing (2011), a rational model with capital adjustment costs faces difficulty in generating sufficient investment volatility. Owing to capital adjustment costs, investment growth in the rational model exhibits about the same volatility as output growth, whereas investment growth in the data is about two times more volatile than output growth. In our model, the excess volatility of perceived productivity growth causes excess volatility of investment, thereby improving the fit with investment volatility in the data.

Lustig, Van Nieuwerburgh, and Verdelhan (2008) document that both the wealthconsumption ratio and the return on the consumption claim are volatile, a challenge for traditional leading asset-pricing models. ${ }^{4}$ We show that extrapolation can help produce high volatility for both the wealth consumption ratio and the return on the aggregate wealth,

\footnotetext{
${ }^{4}$ In a recent paper, Ai (2010) proposes a learning model in production economy which can account for the dynamics of the wealth consumption ratio. However, Ai (2010) does not address the conditional moments of the stock returns or the quantities.
} 
again owing to excessive variation in expectations about technological growth.

Several previous studies examine the effects of extrapolative expectations. In a partial equilibrium model, Barsky and DeLong (1993) show that persistence in expected dividend growth contributes to volatility in price-dividend ratios. Cecchetti, Lam, and Mark (2000), Choi (2006) and Lansing (2006) study extrapolative expectations in an exchange economy. They show that extrapolative bias can help explain a high equity premium and high stock market volatility. Fuster, Laibson, and Mendel (2010) study the implications for macroeconomic fluctuations of natural expectations (a weighted average of rational and extrapolative expectations) in an endowment economy with constant relative risk aversion (CRRA) preferences. Empirically, De Bondt and Thaler (1985), Poterba and Summers (1988), Lakonishok, Shleifer, and Vishny (1994), and La Porta, Lakonishok, and Vishny (1997) provide evidence of overreactions, which suggests that extrapolation can help explain stylized facts about predictability of aggregate market returns and the cross-section of stock returns. ${ }^{5}$

Our approach builds on a growing literature on long-run risk, especially as applied to production economies. Bansal and Yaron (2004) demonstrate that in an endowment economy with long-run risk in consumption and recursive preferences, consumption and asset-price properties can be reconciled with moderate risk aversion and an IES greater than one. Our paper differs in examining a production economy, so that aggregate consumption is endogenous, and in using a much lower risk aversion coefficient (which is arguably more realistic) in our calibration. Tallarini (2000) works with a representative agent in a production economy with recursive preferences, but his model focuses on the case of a fixed IES and no capital adjustment costs. He shows that even with high risk aversion, his model has implications for macroeconomic quantities comparable to those obtained by Kydland and Prescott (1982). The production economy of Tallarini (2000) can generate a high Sharpe ratio with an extremely high risk aversion. His model, however, generates a very low equity premium.

The most closely related paper to this one is Kaltenbrunner and Lochstoer (2010) (KL (2010) hereafter), who show that long-run consumption risk can be endogenously generated even if the technology is i.i.d.. Our model extends that of KL (2010) by introducing extrapolation; their model is the special case of ours in which there is no extrapolative bias.

\footnotetext{
${ }^{5}$ There is still, however, debate about the role of extrapolation in the cross-section of returns. For example, Daniel and Titman (2006) provide evidence suggesting that extrapolation of fundamentals is unlikely to be the main force behind the observed value premium.
} 
Building on the evidence of shifts in expected productivity growth (e.g., Beaudry and Portier (2006) and Edge, Laubach, and Williams (2007)), Croce (2010) studies a model featuring long-run productivity risk directly. KL (2010) and Croce (2010) feature an IES larger than one and can produce a high Sharpe ratio with relatively low risk aversion. However, the volatility of equity returns is still very low, and hence this approach does not replicate the high equity premium found in the data.

An earlier literature studies asset prices in a production economy with habit preferences, including influential papers by Jermann (1998), Lettau and Uhlig (2000), and Boldrin, Christiano, and Fisher (2001). Methodologically, our paper is closely related to Jermann (1998), who finds that the combination of capital adjustment costs and habit preferences can generate a low risk-free rate, a high equity premium, high volatility of excess returns, and high relative investment and low consumption volatility. More recently, Campanale, Castro, and Clementi (2010) show that a production economy with convex capital adjustment costs and disappointment aversion can produce a high equity premium as well.

These models typically feature a very low IES, and hence imply excessively high volatility for the risk-free rate. This tends to result in an abnormally large term premium. Our model produces a low volatility for the risk-free rate and high volatility for the equity returns simultaneously. ${ }^{6}$

In sum, in this paper, we show that incorporating extrapolative bias into a standard real business cycle model substantially improves the model's ability to match both macroeconomic quantities and asset prices.

\section{A Production-Based Model with Extrapolation}

We now present a DSGE model with extrapolative expectations to examine the joint dynamics of consumption, investment, output, and asset prices. For simplicity, we consider a representative agent economy. In the special case where information is complete and there is no extrapolative bias, our model is the same as the permanent shock model of KL (2010). We thus follow their notations in setting up the model.

\footnotetext{
${ }^{6}$ There is also a large literature examining the role of Bayesian learning in asset markets (e.g., Timmerman (1993, 1996), Veronesi (1999), Brennen and Xia (2001), and Brandt, Zeng, and Zhang (2004)).
} 


\subsection{Household's Preferences}

We use the terms investor, individual, and household interchangeably to refer to the representative household. Following the long-run risk literature, we assume that the representative household's preferences over the uncertain consumption stream $C_{t}$ are described by the Epstein-Zin-Weil recursive utility function (e.g., Epstein and Zin (1989) and Weil (1989)),

$$
V_{t}=\hat{\mathbf{E}}_{t}\left[(1-\beta) C_{t}^{\frac{1-\gamma}{\theta}}+\beta\left(\hat{\mathbf{E}}_{t} V_{t+1}^{1-\gamma}\right)^{\frac{1}{\theta}}\right]^{\frac{\theta}{1-\gamma}},
$$

where $\hat{\mathbf{E}}_{t}(\cdot)$ is the expectation under the individual's subjective belief conditional on information available up to time $t$, the parameter $0<\beta<1$ is the time discount factor, $\gamma \geq 0$ is the risk-aversion parameter, $\psi \geq 0$ is the intertemporal elasticity of substitution (IES) preference parameter, and

$$
\theta=\frac{1-\gamma}{1-\frac{1}{\psi}}
$$

The sign of $\theta$ is determined by the values of risk aversion and IES. When the risk aversion parameter exceeds the reciprocal of IES, the individual prefers early resolution of the uncertainty of consumption path. Hence, these preferences allow for a preference over the timing of the resolution of uncertainty.

The Euler equation describing the representative individual's optimization holds under the individual's belief, which, owing to extrapolative bias, generically does not match the true probability distribution. Thus, the pricing kernel is (e.g., Bansal and Yaron (2004)):

$$
m_{t+1} \equiv \log \left(M_{t+1}\right)=\theta \log \beta-\left(\frac{\theta}{\psi}\right) g_{t+1}+(\theta-1) r_{a, t+1},
$$

where $r_{a, t+1}$ is the logarithm of the gross return on an asset that delivers aggregate consumption as its dividends each period. For any continuous return $r_{t+1}=\log \left(R_{t+1}\right)$, including the one on the consumption claim,

$$
\hat{\mathbf{E}}_{t}\left[\exp \left(m_{t+1}+r_{t+1}\right)\right]=1
$$

The expectation operator $\hat{\mathbf{E}}_{t}(\cdot)$ applies to the individual's biased subjective belief; this is the key difference from a rational expectations model. 


\subsection{Productivity, Capital Accumulation, and Belief Update}

There is a representative firm owned by the representative household, and the output, $Y_{t}$, is produced by a constant return-to-scale neoclassical production function:

$$
Y_{t}=\left(A_{t} L_{t}\right)^{1-\alpha} K_{t}^{\alpha}
$$

where $L_{t} \equiv 1$ is the normalized labor supply, ${ }^{7} A_{t}$ is the production-enhancing technology, and the capital level, $K_{t}$, evolves as

$$
K_{t+1}=\left(1-\delta_{K}\right) K_{t}+\phi\left(\frac{I_{t}}{K_{t}}\right) K_{t}
$$

where $I_{t}$ is the investment in period $t, \delta_{K}$ is the rate of depreciation of the capital, and $\phi(\cdot)$ is a concave function that allows for convex capital adjustment costs,

$$
\phi\left(\frac{I_{t}}{K_{t}}\right)=a_{1}+\frac{a_{2}}{1-\frac{1}{\xi}}\left(\frac{I_{t}}{K_{t}}\right)^{1-\frac{1}{\xi}}, \xi>0
$$

The adjustment cost is parameterized inversely by $\xi$. Following Boldrin, Christiano, and Fisher (2001), the constants $a_{1}$ and $a_{2}$ are set such that there are no adjustment costs in the nonstochastic steady state. The adjustment cost allows the shadow price of installed capital to diverge from the price of an additional unit of capital, and hence it permits variation in Tobin's $Q$. The aggregate resource constraint is

$$
Y_{t}=C_{t}+I_{t}
$$

where $C_{t}$ is the aggregate consumption. Labor is paid at its marginal product. Thus, wages, $\omega_{t}$, and firm dividend payouts, $D_{t}$, satisfy $\omega_{t}=(1-\alpha) Y_{t}$, and $D_{t}=\alpha Y_{t}-I_{t}$, respectively. Letting the productivity growth rate be denoted by

$$
g_{A, t}=\log \left(\frac{A_{t}}{A_{t-1}}\right)
$$

\footnotetext{
${ }^{7}$ In other words, we assume an exogenous wage process such that it is optimal for the firm to always hire at full capacity $\left(L_{t}=1\right)$. In this case, one can show that the operating profit function of the representative firm is linearly homogenous in capital (see KL (2010)).
} 
we assume that the dynamics of the data-generating process for the productivity growth satisfy

$$
g_{A, t+1}=\mu_{A}+\sigma_{A} \epsilon_{A, t+1}
$$

where $\epsilon_{A, t+1}$ is i.i.d. standard normal. We assume that $\sigma_{A}$ is known to the representative individual, but that the true growth rate in productivity $\mu_{A}$ is not observable. In practice, it is much easier to estimate the variance than the mean (see, e.g., Merton (1980)).

The individual is subject to extrapolative bias and updates his perceived growth rate at time $t$ for period $t+1, \hat{\mu}_{t}$, as

$$
\hat{\mu}_{t}=(1-\rho-\tilde{\rho}) \bar{\mu}+\rho \hat{\mu}_{t-1}+\tilde{\rho} g_{A, t},
$$

where $\tilde{\rho}$ reflects the degree of overextrapolation of the most recent growth shock, $\rho$ reflects the persistence of extrapolations made from past growth shocks, and $\bar{\mu}$ is the long-run mean in the individual's belief. In our calibration, we set $\bar{\mu}=\mu_{A}$, the true expected rate of productivity growth. So by equation (7), the individual believes that productivity growth follows

$$
g_{A, t+1}=\hat{\mu}_{t}+\sigma_{A} \hat{\epsilon}_{A, t+1}
$$

where the individual perceives $\hat{\epsilon}_{A, t+1}$ to be i.i.d. standard normal.

By equation (8), the individual takes an average of recent past productivity growth with geometrically declining weights and projects that growth rate forward to forecast the future. The steepness of the decline (measured inversely by $\rho$ ) can be viewed as the degree of myopia in updating. If $\rho$ is small and $\tilde{\rho}$ is large, the individual extrapolates placing a heavy weight on recent realizations of technological growth rates. On the other hand, when $\rho$ is close to one, the individual places heavy weight on distant past growth rates. In a sense, when $\rho$ is small and $\tilde{\rho}$ is large, the individual is both extrapolative and myopic. Finally, in the special case where $\tilde{\rho}=1-\rho$, the above setting is similar to that of Barsky and DeLong (1993). Moreover, in this case, the extrapolative learning matches the 'constant-gain' learning rule, which is popular in adaptive learning literature (see Sargent (1993)).

The learning scheme in equation (8) is quite intuitive as a way of capturing overextrapolation. A possible motivation derives from structural breaks in TFP growth. If individuals believe that a structural break might have occurred, they put less weights on distant past observations and more weights on recent observations. Another possible motivation for the updating rule in equation (8) is time-varying expected TFP growth. 
Indeed, Barsky and DeLong (1993) present an example in which the true long-run growth rate is a random walk, and the optimal estimation of the expected growth rate exactly follows equation (8) with $\tilde{\rho}=1-\rho$. They use this specification to study excess stock market volatility in a partial equilibrium framework. In our general equilibrium framework, to ensure stationarity and the finiteness of asset prices, we always fix $\rho+\tilde{\rho}=0.9999<1$

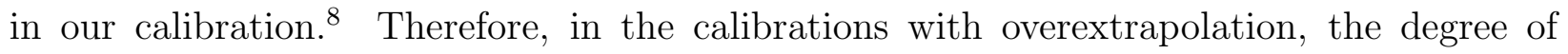
overextrapolation is measured inversely by a single parameter, $\rho$.

Lastly, in principle, based on TFP realizations investors could eventually learn to correct their mistaken extrapolative belief as given in equation (8). However, as is standard in behavioral models, we assume that investors are subject to psychological bias, and are not able to completely 'learn their way out' of their bias. Psychological literature suggests that such imperfect learning can be a consequence of inherent cognitive constraints, or of overconfidence. Also, it could be argued that investors are even less rational than assumed in our model, and in particular do not fully understand the structure of the economy in which they participate. This is probably the case, but for reasons of parsimony we believe it is useful, at least as a first step, to try to understand the consequences of a single deviation from rationality before studying more complicated combinations of psychological effects.

\subsection{Model Solution}

Solving the model numerically is straightforward. Since the quantities in the economy are cointegrated with the aggregate productivity and the problem is homogeneous in $A_{t}$, we first scale variables by the aggregate productivity, then solve the value function with the usual value iteration. We refer to KL (2010) for details on the numerical solution. The only difference from the standard rational model is that, under the perception of the individual, by (9) the dynamics of the state variable, $\hat{\mu}_{t}$, are

$$
\hat{\mu}_{t+1}=(1-\rho-\tilde{\rho}) \mu_{A}+\rho \hat{\mu}_{t}+\tilde{\rho} g_{A, t+1}=(1-\rho-\tilde{\rho}) \mu_{A}+(\rho+\tilde{\rho}) \hat{\mu}_{t}+\tilde{\rho} \sigma_{A} \hat{\epsilon}_{A, t+1},
$$

Thus, $\rho+\tilde{\rho}$ determines the persistence of the perceived technological growth rate under the individual's own belief. Thus, the perceived growth is quite persistent. This property is

\footnotetext{
${ }^{8}$ The results are essentially the same if we set $\rho+\tilde{\rho}=1$, as in Barsky and DeLong (1993). If $\rho+\tilde{\rho}=1$, the perceived growth rate is a random walk as shown in equation (10). Under some preferences, it is possible that the value function is infinite. To rule out this possibility, we set $\rho+\tilde{\rho}<1$. However, for our calibration, the value function is always finite even if $\rho+\tilde{\rho}=1$. Thus, the calibration results would be virtually the same for $\rho+\tilde{\rho}=0.9999$ and $\rho+\tilde{\rho}=1$.
} 
not unique to our extrapolative learning scheme. In an i.i.d growth economy with Bayesian learning on the true mean growth rate, Collin-Dufresne, Johannes, and Lochstoer (2012) show that in the agent's filtration, the mean expected consumption growth rate is timevarying with a unit root.

Once the value function is solved numerically, variables of interest can be obtained. For example, from Epstein and Zin (1989), the log wealth-consumption ratio is

$$
w c_{t} \equiv \log \left(\frac{W_{t}}{C_{t}}\right)=\log \left(\frac{1}{1-\beta}\right)+\left(1-\frac{1}{\psi}\right) \log \left(\frac{V_{t}}{C_{t}}\right)
$$

Following a standard argument of Cochrane (1991), the return on investment is

$$
R_{I, t+1}=\phi^{\prime}\left(I_{t} / K_{t}\right)\left[\alpha\left(\frac{A_{t+1}}{K_{t+1}}\right)^{1-\alpha}+\frac{1-\delta_{K}+\phi\left(I_{t+1} / K_{t+1}\right)}{\phi^{\prime}\left(I_{t+1} / K_{t+1}\right)}-\frac{I_{t+1}}{K_{t+1}}\right] .
$$

The log return on investment is therefore $r_{I, t}=\log \left(R_{I, t}\right)$. Notice that the return on investment is the same as the return on the equity claim. ${ }^{9}$ Finally, it follows from Epstein and Zin (1989), the risk-free rate can be calculated numerically as

$$
r_{f, t}=-\log \left[\hat{\mathbf{E}}_{t}\left(\beta\left(\frac{C_{t+1}}{C_{t}}\right)^{-\frac{1}{\psi}}\left(\frac{V_{t+1}\left(K_{t+1}, \hat{\mu}_{t+1}, A_{t+1}\right)}{\hat{\mathbf{E}}_{t}\left(V_{t+1}^{1-\gamma}\left(K_{t+1}, \hat{\mu}_{t+1}, A_{t+1}\right)\right)^{\frac{1}{1-\gamma}}}\right)^{\frac{1}{\psi}-\gamma}\right)\right]
$$

In calibration, we report results on levered equity market returns, $r_{E, t}$. Following Boldrin, Christiano, and Fisher (1995) and Croce (2010), we introduce constant financial leverage, and the levered excess return is defined as $r_{E, t+1}-r_{f, t} \equiv\left(r_{I, t+1}-r_{f, t}\right)(1+B / E)$, where $B / E$ is the average debt-equity ratio. We set $B / E$ to be $2 / 3$ since the actual debt to equity ratio is around 2/3 (see, e.g., Benninga and Protopapadakis (1990)). We also discuss alternative ways to introduce leverage in Section 3.5.

\subsection{The Basic Idea}

The ability of the model to reconcile a high equity premium and low risk-free rate with low risk aversion comes from the way that extrapolative bias interacts with recursive preferences. Extrapolation bias causes excessive variation in perceived productivity growth, which in

\footnotetext{
${ }^{9}$ As in KL (2010), one can show that the conditions in Restoy and Rockinger (1994) are satisfied, and thus the investment return and the stock return are the same.
} 
turn induces volatile fluctuations in investors' expectations of consumption growth. With recursive preferences, fluctuations in expected consumption growth are priced.

Following Epstein and Zin (1989), we rewrite the pricing kernel as

$$
m_{t} \approx \hat{\mathbf{E}}_{t-1}\left(m_{t}\right)-\left(\gamma \epsilon_{c, t}-\frac{\gamma-\frac{1}{\psi}}{1-\frac{1}{\psi}}\right) \epsilon_{w c, t}
$$

where $\epsilon_{c, t}$ is the short-run shock in consumption growth, and $\epsilon_{w c, t}$ is the shock in the $\log$ wealth-consumption ratio. Under log-linear approximation in the spirit of Campbell (2003) and Bansal and Yaron (2004), the wealth-consumption ratio can be approximated by

$$
w c_{t} \approx A_{0}+A_{1} x_{t}
$$

where $x_{t}$ is the individual's expectation of the consumption growth rate, and the amplification factor $A_{1}$ is usually very large. Thus, long-run risk comes from shocks to the wealthconsumption ratio, or shocks to expected future consumption growth. To generate a highly volatile pricing kernel, which is a prerequisite for matching evidence of a high equity premium, we need a volatile wealth-consumption ratio.

As in a standard long-run risk model,

$$
A_{1} \approx \frac{1-\frac{1}{\psi}}{1-\rho_{x} \kappa_{1}}
$$

where $\rho_{x}$ is the perceived persistence in the perceived expectation of consumption growth, and $\kappa_{1} \approx(W C-1) / W C \approx 1$. Here, $W C$ is the average wealth consumption ratio. With extrapolative expectations, $\rho_{x}$ is extremely close to one in the perception of the individual (see equation (10)). Thus, $A_{1}$ tends to be several times larger than that in a traditional long-run risk model. Moreover, the volatility of the perceived expected growth rate is larger than that in a standard long-run risk model due to extrapolation. Together, equation (15) implies that the wealth-consumption ratio is much more volatile in our extrapolation model than in a standard long-run risk model, consistent with the evidence in Lustig et al. (2008).

Although the TFP shocks are i.i.d. in our model, consumption growth has a persistent and predictable component in equilibrium. Thus, as in KL (2010), long-run risk is endogenously generated as a consequence of consumption smoothing. ${ }^{10}$ However, as we

\footnotetext{
${ }^{10}$ Here, consumption smoothing refers to the fact that the agent use investment to smooth his own consumption. If the agent invests more now, he consumes less now and more in the future. Thus, this
} 
will show in the calibration, extrapolative bias amplifies the effect of the long-run risk substantially by widening the fluctuations in perceived expected productivity growth, and hence in perceived expected consumption growth. Furthermore, as explained in the introduction, substantial investment adjustment costs decrease the covariance between marginal utility of consumption and asset returns, further amplifying risk. This is a key mechanism by means of which our model produces a high equity premium and volatile equity returns. In this sense, long-run risk is generated by investor misperceptions. In sum, the combination of extrapolation, recursive preferences, and adjustment costs produce a large and volatile equity premium.

\section{Calibration}

We now examine different versions of the model to explore the importance of the different model assumptions for explaining stylized facts about asset pricing while replicating salient business cycle evidence about output, consumption and investment volatility. In addition, we also examine the conditional performance of the model such as the return predictability by price-dividend ratio, investment, and aggregate $Q$. As is standard in the real business cycle literature, the model is calibrated at a quarterly frequency. Since the model is in real and per capita form, all calibration is done with real, per capita empirical counterparts.

\subsection{Parameter Choices}

Table 1 reports the parameter values we use for our two benchmark calibrations. We borrow most of the parameter values from the real business cycle literature. Following Boldrin, Christiano, and Fisher (2001), the capital share $(\alpha)$ is set to a value of 0.36 , the quarterly depreciation rate $\left(\delta_{K}\right)$ is set at 0.021 , and the quarterly average log productivity growth rate $\left(\mu_{A}\right)$ is fixed at $0.4 \%$. This set of parameters is chosen to match the long-run growth rate of the economy; these parameters do not substantially affect model dynamics. Finally, we fix the volatility of the productivity growth at $\sigma_{A}=0.041$, the same value as in KL (2010), to match observed output volatility since 1929. As our model is an exogenous growth model, all endogenous variables in the long run grow at the same rate as productivity.

smoothing endogenously generates a predictable component in consumption growth, which is highly priced. However, due to the desire to invest and to take advantage of positive TFP shocks, the agent is willing to bear the long-run risk generated by his own consumption smoothing. 
Mehra and Prescott (1985) suggest that the conventional range of risk aversion should be less than 10. We therefore choose $\gamma=4$ and $\gamma=2$ for our two benchmark calibrations. These risk aversion coefficients are lower than that employed in the existing literature. Our ability to use a smaller level of risk aversion reflects the ability of biased expectations to generate enough risk to replicate the empirical equity premium. By way of comparison, Tallarini (2000), for example, using a risk aversion of 100, and obtains an equity premium of $0.04 \%$, much smaller than its empirical counterpart.

Following Ai (2010) and Croce (2010), we fix the IES $(\psi)$ at 2, which is consistent with estimates of Attanasio and Vissing-Jorgensen (2003), Bansal, Gallant, and Tauchen (2007), Bansal, Kiku, and Yaron (2007), and Binsbergen et al. (2011). For example, the estimated IES ranges from 1.73 to 2.09 in Binsbergen et al. (2011). ${ }^{11}$

Empirical studies do not offer precise guidance for calibrating the pure time discount factor $(\beta)$, capital adjustment costs $(\xi)$, and extrapolative bias $(\rho)$. Given the central role played by these parameters for business cycles and asset returns, we examine reasonable ranges for them to verify whether the model can match the empirical moments.

For example, the time discount parameter $\beta$ is chosen to keep the level of interest rates low. For the capital adjustment cost parameter $\xi$, KL (2010) choose $\xi=18$ and 0.7 for two baseline models, while Jermann (1998) and Boldrin, Christiano, and Fisher (2001) choose $\xi=0.23$. As we show below, reducing the value of $\xi$ (i.e., raising the adjustment costs) tends to improve the performance of our model. We choose an intermediate value of 1.5 for our benchmark calibrations. In addition to the benchmark calibrations, a detailed sensitivity analysis is performed to provide us with insights about the model mechanisms at work.

Since the more innovative feature of the model, overextrapolation, is reflected inversely in the parameter $\rho$, we report results for different values of the extrapolation parameter with benchmark values of $\rho=0.98$ and $\rho=0.95$. Bearing in mind that extrapolative learning here is basically the same as the constant-gain learning in macro literature, a value of $\rho=0.98$ is consistent with existing studies. Orphanides and Williams (2005), for example, choose $\rho=0.98$ to match the inflation forecasts from the Survey of Professional Forecasters (SPF). Milani (2007) estimates a DSGE model on several macroeconomic time series, and find that $\rho=0.9817$ fits the data the best. More recently, using micro-level forecast data, Malmendier

\footnotetext{
${ }^{11}$ In contrast, using aggregate data, early studies, such as Hall (1988) and Campbell and Mankiw (1989), typically found the IES to be much less than 1. However, Vissing-Jorgensen (2002) and Guvenen (2006) point out that there is a downward bias in the IES estimation using aggregate data. Once heterogeneity especially limited asset market participation - is taken into account, the estimated IES is much larger.
} 
and Nagel (2011) also confirm that $\rho \approx 0.98$ is a good approximation for aggregate-level extrapolation parameter.

Since estimates of extrapolation bias from survey data are not very precise and the survey data are not directly about $\mathrm{TFP}^{12}{ }^{12}$ we also consider a stronger extrapolation parameter value as our second benchmark calibration. As argued before, a stronger extrapolation bias should improve the performance of our model since it implies a larger variation in perceived consumption growth. To explore this further, we consider the alternative value for the extrapolation parameter of $\rho=0.95$. To discipline our parameter choice, we verify that the model implied variation of the perceived consumption growth is comparable to that in a standard Bansal and Yaron (2004) economy. As we will show later, with $\rho=0.95$ the modelimplied volatility of the perceived consumption growth rate is indeed of similar magnitude to the volatility of expected growth in a standard long-run risk model.

Although we fix the values for $\mu_{A}, \sigma_{A}, \alpha$, and $\delta_{K}$, we allow $\rho, \psi, \gamma, \beta$, and $\xi$ to vary across different calibrations to match the key moments in the data. As mentioned earlier, we always fix $\rho+\tilde{\rho}=0.9999$ except the cases in which there is no extrapolative bias $(\rho=1$ and $\tilde{\rho}=0)$.

\subsection{Unconditional Moments}

We simulate the model for 400, 000 quarters of artificial data to estimate 'population' values for a variety of statistics. We also consider small sample properties of the model by simulating 400 quarters of artificial data each time and repeating the procedure 1,000 times. The main results are found in Table 2, which includes the summary statistics of both quantities and asset prices from the eight different parameterizations. In general, consumption growth is smoother than output growth, while investment growth is more volatile than output growth, consistent with the data.

\footnotetext{
${ }^{12}$ There are survey data about GDP growth, but usually not about TFP growth. GDP growth can be predictable in a rational DSGE model even if the TFP growth is an i.i.d. process. Thus, it is not trivial to extract the extrapolation parameter on TFP growth from the survey data about GDP growth.
} 


\subsubsection{The Benchmark Calibration}

We consider two benchmark calibrations. The first uses $\rho=0.98$, and risk aversion $\gamma=4$. The second uses a stronger extrapolation bias of $\rho=0.95$ and lower risk aversion of $\gamma=2$.

The output volatility and the mean growth rates of the economy are pinned down by the technology parameters and are chosen to match the data. We therefore omit them and only report the volatility of the variables of interest. With an adjustment cost of $\xi=1.5$ and an extrapolation parameter of $\rho=0.98$, the model generates volatile investment and smooth consumption relative to output, in a magnitude similar to those in the data. In addition, the volatilities of both the investment rate and Tobin's $Q$ are comparable with that in the data. Moreover, in the second benchmark calibration with stronger extrapolation bias, the quantities are even closer to those in the data.

The benchmark model I matches the moments of asset prices well. With a risk aversion coefficient of 4 and an IES of 2, the model produces a sizable equity premium of $5.42 \%$ (continuously compounded), compared with 3.90-6.69\% in the historical data. The volatility of the excess return is $10.37 \%$, slightly smaller than the $15.70-19.42 \%$ range in the data. Since the model matches the macroeconomic quantities, this is a significant success for a production-based model. For example, KL (2010) produce a volatility of only $0.66 \%$ for the excess return on the (unlevered) equity claim in one of their benchmark calibrations. Croce (2010) produces a volatility of $1.60 \%$ for a levered equity claim with a risk aversion coefficient of 30. In addition, this volatility can be further increased if one chooses $\rho=0.95$ as in our benchmark model II. Intuitively, investor overextrapolation causes a perception of high volatility of expected consumption growth; together with recursive preference this can result in high risk premia without high consumption volatility.

The first benchmark calibration also produces smooth interest rates, even smoother than those in the data. This is a significant victory for the model, since standard habit models in production economies are well known to produce an excessively volatile interest rate. For instance, in Boldrin, Christiano, and Fisher's (2001) two-sector calibration with habitformation, the volatility of interest rates is $24.60 \%$, much higher than the typical $1 \%$ in the data.

A usual side effect of highly volatile interest rates is an excessively large term premium (see, e.g., Jermann (1998) and Abel (1999)). Large bond term premia are related to overly volatile interest rates, as term premia are compensation for real interest rate risk. In our 
model, thanks to the high IES, the interest rate is very smooth despite the extrapolative expectations, and hence the term premium is also small, consistent with the data. ${ }^{13}$ For the benchmark model, it produces a downward-sloping real yield curve. The short-term real rate is already low at $1.29 \%$, while the long real rates are an additional 0.70 percentage point lower. This pattern is consistent with the long sample of the UK data, but not consistent with the short sample of the U.S. TIPS data (see, e.g., Piazzesi and Schneider (2006)).

At the bottom of Table 2, we report summary statistics for the perceived expected consumption growth by the individual, and the aggregate wealth portfolio. The perceived expected growth rate in the model is $0.79 \%$. The ratio of the volatility of the perceived expected growth to the volatility of realized growth rate is slightly less than $21 \%$. The perceived expected growth rate is not directly observable, but we can get some sense for the magnitude of this number by comparing with existing studies. In the one channel model of Bansal and Yaron (2004), for example, the volatility ratio of expected growth and realized growth is $34.4 \%$ for quarterly frequency calibration. Thus, the volatility of the perceived growth rate in our calibration does not appear too large.

Owing to the high variation in the perceived expected growth rate, our model produces an annual volatility of the wealth-consumption ratio of about $12.42 \%$, which is about half of that in the data. This is a success compared to the standard long-run risk models; Ai (2010), for example, shows that the standard long-run risk model only produces a volatility of $4.70 \%$ (see Table I in Ai (2010)). From equation (14), this high volatility in the wealth-consumption ratio is the main driving force underlying the high and volatile equity returns. Our model also generates a high volatility of the return on aggregate wealth, again consistent with the data.

Finally, when the extrapolation parameter is $\rho=0.95$, the benchmark model B.II matches the moments in the data even more closely. For example, consumption growth is smoother, and investment growth and asset returns are more volatile.

However, in both benchmark calibrations, the mean return on the wealth portfolio is larger than that in the data, as calculated by Lustig et al. (2008). In the model, the consumption claim is riskier than the firm's dividend payout claim since the payout is less procyclical than consumption. Thus, the return on the consumption claim is too high relative

\footnotetext{
${ }^{13}$ Campbell (2003) argues that extrapolative expectations in general equilibrium tend to lead to volatile interest rates. In our benchmark models, owing to high adjustment costs, the perceived expected consumption growth is not very volatile. This fact, together with a high IES value, results in a smooth riskfree rate.
} 
to the data. We discuss potential resolutions for this issue in section 3.5.

\subsubsection{The Mechanism of the Model}

To identify the key mechanism behind the empirical success of the model, below we follow Jermann (1998) by calibrating the model at different parameter combinations. This way, we can identify which ingredients are key to replicating different aspects of the data.

We start with a calibration (model III) with a very low capital adjustment cost and no extrapolation $\left(\rho=1, \tilde{\rho}=0\right.$, and $\left.\hat{\mu}_{t}=\mu_{A}\right)$, and then sequentially add the adjustment cost and extrapolation into the model. The outcome of model III is consistent with the standard RBC model. Consumption is smooth, and investment is more volatile than output. These patterns are consistent with the quantity data. However, the equity premium is very low (less than 1\%), as is the volatility of the stock return (less than $3 \%$ ). Intuitively, owing to low adjustment costs, the individual can easily smooth consumption by adjusting the amount of investment. This reduces consumption risk and therefore equity risk premium.

In model IV we increase the capital adjustment cost. Not surprisingly, this greatly reduces investment volatility. Consistent with the intuition above, this in turn increases the volatility of consumption growth. So the model sacrifices good matching of this quantity moment, but does have the benefit of raising the equity premium slightly, and generating greater returns volatility.

This type of finding is well known for standard DSGE models (e.g., Jermann (1998)). To produce a high equity premium, the adjustment cost cannot be too small; otherwise, consumption is too smooth, and hence the equity premium is small. However, if the capital adjustment cost is high, the investment volatility is too low compared with the data. Thus, it is hard to match both the quantities and asset prices simultaneously. In two important papers, Jermann (1998) and Boldrin, Christiano, and Fisher (2001) show that introducing habit preference can help to match these stylized facts.

Compared with Model IV, the benchmark calibration I introduces a relatively small extrapolative bias. Owing to bias in expectations, the perceived expected growth rate of productivity varies over time, leading to greater fluctuation in (perceived) optimal investment. For example, after a few positive productivity shocks, the individual perceives that the future growth rate is likely to be very high. Thus, compared with the rational 
case, the individual tends to invest more heavily to exploit this productivity. Similarly, after negative shocks, the individual tends to underinvest relative to the rational case. Therefore, even with a relatively high adjustment $\operatorname{cost}(\xi=1.5)$, the model can produce high volatility of investment growth. With a slight extrapolative bias in the benchmark model I, the investment volatility relative to output increases to 1.73 from 1.30 in model IV.

With extrapolation, benchmark calibration I also generates smoother consumption than in model IV, which is more consistent with the data. Moreover, despite the smoothness of consumption in benchmark model I, the equity return is more volatile, and the equity premium larger. Despite the higher return volatility, the Sharpe ratio of the market increases (consistent with the equity premium puzzle), because the rise in the equity premium is proportionately even larger.

These differences from model IV reflect a key mechanism in our model. Although the volatility of realized consumption growth is smaller in benchmark calibration I, the perceived expected consumption growth rate is more volatile. From the long-run risk literature, we know that the variation of the perceived expected growth rate commands an especially high price of risk. Owing to the persistence in perceived expected growth rates, news regarding future expected growth rates results in large reactions in the price-dividend ratio and the stock return. Since these reactions are negatively associated with the marginal rate of substitution of the representative agent, this effect increases the equity risk premium.

Furthermore, owing to capital adjustment costs, the firm cannot easily alter its investment. For example, after a favorable TFP realization, realized asset returns increase. Meanwhile, the firm pays out more dividends, and hence increases the level of consumption and reduces the marginal utility from consumption. Thus, high capital adjustment costs decrease the covariation between asset returns and the marginal utility from consumption, which in turn increases equity risk. Together, these effects result in a high equity risk premium.

The reason for the higher volatility of the perceived expected consumption growth rate is similar to the reason for higher investment volatility. After favorable productivity shocks, the individual invests more than in the rational case and consumes less in the current period. As a result, he perceives high future consumption growth resulting from high perceived future productivity and the current high investment. Thus, extrapolative bias amplifies the volatility of both investment and perceived expected consumption growth. On the other hand, the extrapolative bias smooths actual consumption growth: with extrapolative 
expectations the representative investor has more incentive to make more investments after good TFP shocks, and less investments after bad shocks; investments tend to absorb more of the payoff variation resulting from TFP shocks, leading to smoother actual consumption growth.

Model $\mathrm{V}$ maintains extrapolation bias, but reduces the adjustment cost by setting $\xi$ to 15. With an extremely low capital adjustment cost, the individual can now easily adjust his investment according to perceptions of growth opportunities, making investment very volatile. This ease in shifting investment in response to opportunities allows the perceived expected consumption growth to become much more volatile. ${ }^{14}$ In the face of a positive shock, the individual consumes less and invests more, and hence perceived expected consumption growth is high.

Despite the high volatility of the perceived expected consumption growth, and hence high long-run risk, the equity premium is still very small in model V. Furthermore, the volatility of the levered equity is just $1.83 \%$, compared with the $10.37 \%$ in benchmark calibration I. This is because with low capital adjustment costs, the firm can easily invest more in the face of a good productivity shock, and thus the firm's payout and consumption are less procyclical or even countercyclical. This effect tends to increase the covariation between asset returns and the marginal utility of consumption, and hence leads to a very low risk premium for the equity claim. ${ }^{15}$

In summary, to generate a high equity premium, it is necessary to have sufficiently high capital adjustment costs as well as extrapolative bias. Extrapolative bias generates high volatility of perceived consumption growth and hence of the pricing kernel. Capital adjustment costs prevent firms from investing so much that dividend payouts become minimally procyclical (or even countercyclical), which would reduce the riskiness of equity. With both model ingredients, there is a high market price of risk, and equity is perceived as very risky, resulting in a high equity premium. We have also developed impulse response functions (not included in the paper). Not surprisingly, the message they provide is very similar to that of the above calibrations.

\footnotetext{
${ }^{14}$ However, the volatility of actual consumption remain relatively small, since individuals are also in part adjusting investment to smooth consumption.

${ }^{15}$ Our findings with low adjustment costs are consistent with Carceles-Poveda and Giannitsarou (2008), who study the effects of constant gain learning on asset prices in a production economy. With CRRA preferences and no adjustment costs, they find that the effects on volatility and the equity premium are quite small.
} 
If we reduce $\rho$ to 0.98 and 0.95 (as in the benchmark models I and II), the perceived productivity growth becomes more volatile, and hence the volatility of investment and perceived expected consumption growth is also larger. Relative investment volatility increases to 1.73 and 2.42, respectively, which is very close to that in the data. Moreover, due to high long-run consumption risk, the equity premium is still very large despite a lower risk aversion in benchmark model II, and equity returns are highly volatile. The risk-free rate is also slightly more volatile owing to greater volatility of the perceived expected consumption growth rate.

In models VI, we vary the IES from the benchmark of 2 to 3. As the IES increases, consumption becomes smoother, and the equity premium becomes larger. This is consistent with the findings in KL (2010): increasing IES tends to decrease the volatility of realized consumption growth while increasing the volatility of expected consumption growth volatility. In all of the calibrations, we keep the IES greater than 1 because of the well-known finding from the long-run risk literature that the performance of the model will be poor if the IES is less than 1. Finally, in model VII, the risk aversion coefficient is decreased to a value of 2. Comparing model VII with the benchmark model I, smaller risk aversion decreases the equity premium and the Sharpe ratio, consistent with the findings in Tallarini (2000). Also consumption volatility is smaller when risk aversion is lower, again consistent with Tallarini (2000).

In sum, the combination of extrapolative biases, capital adjustment costs, and recursive preference seems to account for the empirical success of our model. However, our model does not match the moments for the aggregate wealth portfolio and the firm's dividend claim simultaneously. We shall return to these drawbacks of our model in Section 3.5, and suggest potential resolutions.

\subsection{Return Predictability}

In the data, excess returns are predictable by the dividend-price ratio (e.g., Campbell and Shiller (1988) and Fama and French (1988)), aggregate $Q$ (e.g., Kothari and Shanken (1997) and Pontiff and Schall (1998)), and the investment rate (IK) (e.g., Cochrane (1991)). Despite a debate over robustness (e.g., Goyal and Welch (2007)), the trend of the literature favors

such variables having power to predict returns (e.g., Ang and Bekaert (2007), Campbell and Thompson (2008), Cochrane (2008), and Rapach, Strauss, and Zhou (2010)). 
We now show that with extrapolation bias, our model can help reproduce these empirical patterns. To do so, we perform the standard regression of future return on the dividendprice ratio. When the perceived technology expected growth rate, $\hat{\mu}_{t}$, is high, the firm invests more and the dividend payout is small. Thus, the dividend-price ratio is small. In this circumstance, an econometrician would forecast a lower expected return, in anticipation of lower productivity growth, than do extrapolative individuals. Thus, the dividend-dividend ratio positively predicts future returns in the model.

To quantify this, we regress the 1-, 3-, and 5-year stock market excess returns onto the lagged dividend-price ratio. Table 3 reports both regression coefficients and $R^{2}$ statistics. The results are based on 1,000 simulations, each with 400 quarters of simulated data. Both the median values and the $95 \%$ confidence intervals are reported.

It is well known that in the data, the coefficients are positive and the $R^{2}$ s increase with time horizon. Our model replicates this feature for both coefficients and $R^{2}$ statistics. Moveover, as we increase extrapolative bias (a smaller $\rho$ ), the predictive power of the dividend-price ratio is stronger. In addition, in untabulated analysis, we find that the return predictability results based on a long sample with 400,000 observations remain similar to those based on small samples. Although the return predictability in our model is comparable to, or stronger than, that in many existing studies, the predictive power of the dividend-price ratio for returns in the model is still not as strong as that in that data. In the data, the 5 -year $\mathrm{R}^{2}$ is typically higher than $25 \%$.

Intuitively, if extrapolative bias is strong, then after a few good shocks to productivity growth, the individual is more overoptimistic about the future productivity growth. Hence, the firm invests more and the dividend is especially low. This reduces the price-dividend ratio, and makes the future return reversal especially strong since on average the future realized productivity growth is much lower than the individual's expectation. At the opposite extreme, if there is no extrapolation bias, there is no return predictability. These findings are consistent with those of $\mathrm{Ai}$ (2010). With rational learning in a production-based long-run risk model, Ai (2010) finds that the price-dividend ratio predicts excess returns in the wrong direction.

Analogously, the investment rate (IK) and Tobin's $Q$ should also predict future equity returns. After a few favorable shocks to productivity growth, the individual is overoptimistic about future productivity growth, and hence the firm tends to invest more to exploit technology growth. Thus, IK is large, and owing to adjustment costs, Tobin's $Q$ is also large. 
However, on average the future realized productivity growth is lower than the individual's expectation. Thus, the value of the firm is expected to decline from the viewpoint of the econometrician who analyzes the historical data.

In Table 3, we also regress excess returns on lagged investment rates and aggregate $Q$. Consistent with the data, both investment rates and aggregate $Q$ negatively predict future returns. If we eliminate extrapolation bias by setting $\rho=1$, there is no return predictability by the investment rate or aggregate $Q$. On the other hand, as we increase extrapolative bias (i.e., reduce the value of $\rho$ ), the predictive abilities of IK and $Q$ become stronger. The intuition is similar as before. These results highlight the key role of extrapolation in explaining the conditional moments of returns in a production economy.

In sum, extrapolative bias not only helps match the first two unconditional moments of the data, it also generates predictive patterns in returns as observed in the data.

\subsection{Implied Consumption Dynamics}

It is important to verify whether the implied consumption dynamics in the model resemble those in the data. In the data, the predictable component in consumption growth is small. So we next verify that the high equity premium is not due to an excessively predictable component in consumption growth. Table 4 presents summary statistics for the consumption growth from the simulated data.

The general pattern is that the autocorrelation of consumption growth is very small, especially for a high value of extrapolative bias $\rho$. For our benchmark case I, the first-order autocorrelation is only $4 \%$. Even for the case of $\rho=0.95$, the autocorrelation of consumption growth is still only $20 \%$. Thus, the model does not produce an excessively predictable component in consumption. Again, we report both the median value and $95 \%$ confidence intervals from 1,000 simulations, each with 400 quarters of observations. Moreover, we also present results for different values of the extrapolative bias parameter and adjustment costs.

In general, increasing extrapolative bias tends to raise the predictable component of consumption growth and the volatility of consumption growth. Intuitively, when the individual is more extrapolative, his perceived technology growth rate varies more, resulting in greater variation in consumption growth. In addition, as shown in Panels $\mathrm{C}$ and $\mathrm{D}$, increasing the adjustment costs tend to reduce consumption predictability since it is 
difficult to smooth consumption with high adjustment costs. In particular, consumption is less predictable in our benchmark model I with extrapolation than in model III without extrapolation but with smaller adjustment costs. In summary, consumption growth in our benchmark model (Panels A and B) is not excessively predictable compared with the data.

In unreported analysis, we also study consumption dynamics by changing the IES. In general, a high IES leads to more predictable and volatile consumption growth. If the IES is larger, the individual can easily substitute consumption intertemporally. Hence, in the face of a positive (negative) technology shock, the individual can invest more (less) now and consume less (more) in the future, raising the importance of the predictable component in the growth rate.

\subsection{Limitations and Potential Resolution}

We have seen that the model has many empirical successes. We now consider some limitations of the model. In our production-based model, it is hard to simultaneously match the moments for both the firms' payout claim and the aggregate consumption claim. The consumption claim is riskier than the firm's (unlevered) dividend payout claim, since the payout is less procyclical than consumption. In the data aggregate stock market dividends are highly procyclical; dividend payout in the model is not as procyclical. This raises the concern about the direct comparison of the capital claim to the aggregate stock market.

As pointed out by KL (2010), there are good reasons to not regard the payout from the one-sector representative firm in this model as equivalent to the dividend from the aggregate stock market. In reality, the sector of publicly traded firms is only a small fraction of all productive capital. So it may be possible to improve the performance of the model with respect to the aggregate wealth portfolio and the dividend payout claim by introducing additional productive sectors. In our current setting, everything is driven by one shock, the TFP shock, making it is hard to match aggregate consumption and dividends simultaneously. With an additional productive sector, it would be possible to delink consumption and dividends, and hence potentially match both the consumption and dividend claim jointly.

Another approach is to follow previous studies by defining equity market dividends as a levered claim to the consumption stream (among others, see Abel (1999) and Bansal and Yaron (2004)). This way, the dividend claim is riskier than the consumption claim, and 
potentially the model can match moments for the consumption claim and the dividend claim simultaneously.

Finally, since the aggregate wealth portfolio is unobservable, it is very hard to estimate its mean return. Thus, it is possible that the true average excess return on aggregate wealth is higher than the value estimated by Lustig et al. (2008). Indeed, with annual data, the standard deviation of this estimation is about $1 \%$ per year. Hence, it is possible that the true average excess return on the wealth portfolio is $4-5 \%$, which would be more consistent with our benchmark calibration.

Moreover, Bansal, Kiku, and Yaron (2012) find that past consumption predicts the price dividend ratio too strongly in the habit model, owing to the backward-looking feature in the surplus ratio. In some sense, owing to extrapolative bias, our model is also backward-looking. Thus, our model can potentially have the same problem as the external habit models. For example, if we regress the log price-dividend ratios onto past consumption growth rates, we have an $R^{2}$ of about $9 \%$ for our benchmark calibration II, whereas in the data this value is only about $1 \%$.

One potential approach to reducing the predictive ability of consumption is to introduce additional shocks into the model. For example, Croce (2010) introduces both short-run and long-run shocks in technology growth. A richer setup could potentially further improve the performance of the model in terms of the predictability of the price-dividend ratio by past consumption growth. However, the purpose of the current paper is to use a simple production-based model to illustrate how extrapolation bias can help account for many otherwise-puzzling patterns in the data.

\section{Further Implications of the Model}

In this section, we examine two additional implications of the model. First, owing to extrapolation, the model implies that the perceived technological growth rate, $\hat{\mu}_{t}$, will negatively predict returns. Second, the model implies that the aggregate investment rate is positively related to perceived technological growth.

Although the state variable is unobservable (just as is the surplus ratio in the habitformation model and the expected growth rate in the long-run risk model), one can construct a proxy for our state variable from the historical data. As observable proxies for $\hat{\mu}_{t}$, we use 
an exponentially weighted moving average of realized GDP growth from Saint Louis FED and of realized TFP growth from Bureau of Labor Statistics (BLS). Since benchmark model II matches the data better, the exponential decay parameter $\tilde{\rho}$ is set to be 0.95 . Our results remain similar if this value is 0.98 as in benchmark model I. The first proxy based on GDP is indirect; the second proxy based on TFP is more directly linked to the state variable in our model. However, the second proxy is more subject to misspecification and measurement errors. We thus use the first proxy for our main analysis and use the second for robustness checks.

We first consider the implication for return predictability. Table 5 shows that the proxy for the perceived growth rate can indeed significantly negatively predicts future excess market returns in the data. We report $t$-statistics calculated from Newey and West (1987) standard errors, Hansen and Hodrick (1980) standard errors, and Hodrick (1992) standard errors. Ang and Bekaert (2007) show that Newey-West standard errors tend to overreject the null, whereas Hodrick's standard errors tend to underreject the null.

We find that the predictive power of the perceived expected growth is statistically significant. In terms of economic magnitude, a one-standard-deviation-increase in the perceived expected growth leads to about a $3.65 \%$ decrease in subsequent annual returns. The same pattern, although slightly weaker, remains if we use the alternative proxy for $\hat{\mu}_{t}$, the smoothed average of realized TFP growth from BLS. Finally, using Livingston Survey data, Campbell and Diebold (2009) and Goetzmann et al. (2010) find that the forecasted growth rate is also negatively related to future aggregate returns, lending further support for our model. In addition, in cross-sectional analysis, Imrohoroglu and Tuzel (2011) show that firm-level TFP is positively related to contemporaneous stock returns and negatively related to future excess returns, consistent with our model as well. In the model, the predictive power of the perceived growth $\hat{\mu}_{t}$ is very similar to that of the dividend-price ratio, IK, and $\mathrm{Q}$ as shown in Table 3 since the dividend-price ratio, IK, and Q are all highly correlated to the state variable $\hat{\mu}_{t}$. Thus, comparing Tables 3 and 5 , the predictive power of $\hat{\mu}_{t}$ in the model is similar to that in the data.

In contrast, if we use the negative output gap (NGAP) of Cooper and Priestly (2009) as a proxy for 'true expected growth' in the data-generating process, ${ }^{16}$ the opposite results follows, as shown in the last panel of Table 5. This confirms the findings of Cooper and Priestly (2009). This distinct predictive power of perceived expected growth and 'true'

\footnotetext{
${ }^{16}$ The output gap measures the difference between the industrial production and its long-run deterministic trend. Thus, the negative output gap can positively predict future output growth.
} 
growth highlights the key role of investor perception for asset prices.

Moreover, Table 6 shows that it is indeed true that high NGAP forecasts high future GDP growth and productivity growth in the data. By contract, the predictive ability of $\hat{\mu}_{t}$ for GDP and TFP growth is much weaker and is opposite to that of NGAP. This negative predictive power might be due to the initial inefficient overinvestment and the subsequent decrease in productivity after a positive shock to the perceived expected growth.

The surplus ratio in the habit-formation model could also be approximated by smoothed average of past growth rates, a variable similar to our proxy for the perceived expected growth rate. Thus, the habit-formation model would have exactly the same prediction as ours. However, after favorable shocks, the individual in the habit model expects a lower future return, whereas the individual in our model does not anticipate a lower subsequent return.

Using survey data on investor expectations, Durell (2001) and Vissing-Jorgensen (2003) show that in good times, when stock prices are high, investors do not expect lower returns. If anything, the opposite holds. However, investors are supposed to perceive and accept such lower returns in habit models owing to high risk tolerance. In contrast, our model is consistent with this survey evidence as the individual in our model does not perceive a lower future return after good shocks.

Although our model is for the aggregate market, La Porta (1996) focuses on analyst expectations in the cross-section and finds that stocks with the highest growth forecasts earn much lower subsequent returns than stocks with the lowest growth forecasts, potentially consistent with the cross-sectional extension of our current model.

We now turn to the implication of the model for the determinants of the aggregate investment rate. ${ }^{17}$ The model implies that the perceived expected growth rate should be positively correlated with the aggregate investment rate. The top panel of Figure 1 plots the proxy for our state variable and the investment rate, both calculated from the data. The model predicts a strong comovement between this two variables, and this figure confirms this prediction. Owing to the high autocorrelation of the series in levels, the bottom panel in Figure 1 plots the four-quarter differences in investment rates, a measure used by Hassett and Hubbard (1997) and Philippon (2009), and the four-quarter differences in $\hat{\mu}_{t}$. It confirms the strong comovement as well.

\footnotetext{
${ }^{17}$ It is well-known that $Q$ does not have much power in determining the investment rate. The existing literature typically attributes this failure to measurement errors in $Q$.
} 
Table 7 reports the results from a formal regression analysis by regressing investment rates (in difference) onto lagged perceived expected growth rates and lagged cash flow. It is wellknown that the stock market based measure of $Q$ performs poorly in predicting investment rates, while the cash flow can forecast investment rates better. Our results confirm the predictive ability of cash flow. However, the perceived expected growth is a much stronger predictor of the investment rates. Moreover, after controlling for the perceived growth, cash flow is no longer significant. Finally, as a comparison, the explanatory power of our proxy is similar to the bond's $Q$ in Philippon (2009).

In sum, with different proxies for our state variable, we find preliminary support for the two direct testable implications of the model.

\section{Conclusion}

Considerable evidence from the psychology of judgment and from investor behavior suggests that individuals tend to overextrapolate small samples of past performance in forecasting future performance. Standard attempts to resolve the equity premium puzzle based on habit formation or long term risk in endowment economies have not been immediately successful in production economies owing to endogenous consumption and dividend payout smoothing. Existing models typically imply interest rates that are too volatile or excess stock returns that are too smooth. By introducing extrapolation into an otherwise standard dynamic stochastic general equilibrium model with capital adjustment costs, we reproduce the major stylized facts about both macroeconomic quantities and capital market prices as observed in the data. The key to this is the interaction of recursive preferences, adjustment costs, and extrapolation bias. 


\section{Appendix}

To solve the model numerically, we follow the standard value iteration algorithm with Chebyshev regression (e.g., Judd (1998) and KL (2010)). Since the quantities in the economy are cointegrated with the aggregate productivity, $A_{t}$, we first scale quantities by the aggregate productivity. We use hats to denote the scaled variables, and lower cases to denote log values:

$$
\begin{aligned}
& \hat{c}_{t}=\log \left(\frac{C_{t}}{A_{t}}\right), \hat{k}_{t}=\log \left(\frac{K_{t}}{A_{t}}\right), \quad \hat{\imath}_{t}=\log \left(\frac{I_{t}}{A_{t}}\right), \\
& \hat{y}_{t}=\log \left(\frac{Y_{t}}{A_{t}}\right)=\log \left(A_{t}^{-\alpha} K_{t}^{\alpha}\right)=\alpha \hat{k}_{t}, \quad a_{t}=\log \left(A_{t}\right) .
\end{aligned}
$$

The social planner's problem is

$$
V_{t}\left(K_{t}, \hat{\mu}_{t}, A_{t}\right)=\max _{C_{t}, I_{t}} \hat{\mathbf{E}}_{t}\left[(1-\beta) C_{t}^{\frac{1-\gamma}{\theta}}+\beta\left(\hat{\mathbf{E}}_{t}\left[V\left(K_{t+1}, \hat{\mu}_{t+1}, A_{t+1}\right)^{1-\gamma}\right]\right)^{\frac{1}{\theta}}\right]^{\frac{\theta}{1-\gamma}}
$$

Since the problem is homogeneous, we can re-define

$$
V_{t}\left(K_{t}, \hat{\mu}_{t}, A_{t}\right) \equiv \hat{V}_{t}\left(\frac{K_{t}}{A_{t}}, \hat{\mu}_{t}\right) \cdot A_{t}
$$

The maximization problem can be rewritten as

$$
\hat{V}_{t}\left(\frac{K_{t}}{A_{t}}, \hat{\mu}_{t}\right)=\max _{C_{t}, I_{t}}\left[(1-\beta)\left(\frac{C_{t}}{A_{t}}\right)^{\frac{1-\gamma}{\theta}}+\beta\left(\hat{\mathbf{E}}_{t}\left[\hat{V}\left(\frac{K_{t+1}}{A_{t+1}}, \hat{\mu}_{t+1}\right)^{1-\gamma} \cdot\left[\frac{A_{t+1}}{A_{t}}\right]^{1-\gamma}\right]\right)^{\frac{1}{\theta}}\right]^{\frac{\theta}{1-\gamma}}
$$

Taking logarithm on both sides of the above equation, we have

$$
\begin{aligned}
& \hat{v}_{t}\left(\hat{k}_{t}, \hat{\mu}_{t}\right) \equiv \log \hat{V}_{t}\left(\frac{K_{t}}{A_{t}}, \hat{\mu}_{t}\right) \\
= & \left.\frac{\theta}{1-\gamma} \max _{C_{t}, I_{t}} \log \left\{\left[(1-\beta)\left(\frac{C_{t}}{A_{t}}\right)^{\frac{1-\gamma}{\theta}}+\beta\left(\hat{\mathbf{E}}_{t}\left[\hat{V}\left(\frac{K_{t+1}}{A_{t+1}}, \hat{\mu}_{t+1}\right)^{1-\gamma} \cdot\left[\frac{A_{t+1}}{A_{t}}\right]\right)^{1-\gamma}\right]\right)^{\frac{1}{\theta}}\right]\right\} \\
= & \frac{\theta}{1-\gamma} \max _{\hat{c}_{t}, \hat{\iota}_{t}} \log \left\{\left[(1-\beta) e^{\frac{1-\gamma}{\theta} \hat{c}_{t}}+\beta\left(\hat{\mathbf{E}}_{t}\left[e^{\left[\hat{v}_{t+1}\left(\hat{k}_{t+1}, \hat{\mu}_{t+1}\right)+g_{A, t+1}\right](1-\gamma)}\right]\right)^{\frac{1}{\theta}}\right]\right\}
\end{aligned}
$$


Thus, the maximization problem is

$\hat{v}_{t}\left(\hat{k}_{t}, \hat{\mu}_{t}\right)=\frac{\theta}{1-\gamma} \max _{\hat{\imath}_{t}} \log \left\{\left[(1-\beta) e^{\frac{1-\gamma}{\theta} \hat{c}_{t}}+\beta\left[\hat{\mathbf{E}}_{t}\left(e^{(1-\gamma) \cdot\left[v_{t+1}\left(\hat{k}_{t+1}, \hat{\mu}_{t+1}\right)+\left(\hat{\mu}_{t}+\sigma_{A} \hat{\epsilon}_{A, t+1}\right)\right]}\right)\right]^{\frac{1}{\theta}}\right]\right\}$,

where $\hat{\epsilon}_{A, t+1}$ is standard normal under the individual's perception. The dynamics of the state variables are

$$
\hat{\mu}_{+1}=(1-\rho-\tilde{\rho}) \mu_{A}+\rho \hat{\mu}_{t}+\tilde{\rho} g_{A, t+1},
$$

and

$$
\hat{k}_{t+1}=\log \left\{\left(1-\delta_{K}\right) \exp \left(\hat{k}_{t}\right)+\phi\left(\exp \left(\hat{\imath}_{t}-\hat{k}_{t}\right)\right) \exp \left(\hat{k}_{t}\right)\right\}-g_{A, t+1}
$$

However, from the individual's perspective,

$$
\hat{\mu}_{t+1}=(1-\rho-\tilde{\rho}) \mu_{A}+(\rho+\tilde{\rho}) \hat{\mu}_{t}+\tilde{\rho} \hat{\epsilon}_{A, t+1},
$$

and

$$
\hat{k}_{t+1}=\log \left(\left(1-\delta_{k}\right) \exp \left(\hat{k}_{t}\right)+\phi\left(\exp \left(\hat{\imath}_{t}-\hat{k}_{t}\right)\right) \exp \left(\hat{k}_{t}\right)\right)-\hat{\mu}_{t}-\sigma_{A} \hat{\epsilon}_{A, t+1} \text {. }
$$

The last budget constraint is

$$
\hat{\imath}_{t}=\log \left(\exp \left(\alpha \hat{k}_{t}\right)-\exp \left(\hat{c}_{t}\right)\right)
$$

To solve the maximization problem numerically, we parameterize the value function with a 5 th order Chebyshev orthogonal polynomial over a $6 \times 6$ Chebyshev grid for the state variables $(\hat{k}, \hat{\mu})$. We follow the value function iteration algorithm in KL (2010). In particular, assume that the value function is $\Psi_{n}(\hat{k}, \hat{\mu})$ at iteration $n$. For each grid point for the state variables $(\hat{k}, \hat{\mu})$, we use a numerical optimizer to find the policy $\left(\hat{\imath}_{t}^{*}\right)$ that maximizes the value function

$\hat{v}_{t}^{*}\left(\hat{k}_{t}, \hat{\mu}_{t}\right)=\frac{\theta}{1-\gamma} \max _{\hat{\imath}_{t}} \log \left\{\hat{\mathbf{E}}_{t}\left[(1-\delta) e^{\frac{1-\gamma}{\theta} \hat{c}_{t}}+\delta\left[\hat{\mathbf{E}}_{t}\left(e^{(1-\gamma) \cdot\left[\Psi_{n}\left(\hat{k}_{t+1}, \hat{\mu}_{t+1}\right)+\left(\hat{\mu}_{t}+\sigma_{A} \hat{\epsilon}_{A, t+1}\right)\right]}\right)\right]^{\frac{1}{\theta}}\right]\right\}$,

where Gauss-Hermite quadrature with 5 nodes is used to approximate the expectations operator. We then regress the new value $\hat{v}^{*}$ onto state variables $\hat{k}$, and $\hat{\mu}$ in order to update the coefficients of the polynomial for the value function. This way, we can obtain the new Chebyshev polynomial $\Psi_{n+1}(\hat{k}, \hat{\mu})$ at iteration $n+1$. 
After we obtain the value function and the corresponding policy function, we can compute variables of interest. For example, the perceived consumption growth rate is

$$
\begin{aligned}
\hat{\mathbf{E}}_{t}\left[\log \left(\frac{C_{t+1}}{C_{t}}\right)\right] & =\hat{\mathbf{E}}_{t} \log \left(\frac{\hat{C}_{t+1}}{\hat{C}_{t}} \frac{A_{t+1}}{A_{t}}\right) \\
& =\hat{\mathbf{E}}_{t}\left(\hat{c}_{t+1}-\hat{c}_{t}+\hat{\mu}_{t}+\sigma_{A} \hat{\epsilon}_{A, t+1}\right) .
\end{aligned}
$$

The risk free rate can be computed by

$$
\begin{aligned}
r_{f, t} & =-\log \left[\hat{\mathbf{E}}_{t}\left(\beta\left(\frac{C_{t+1}}{C_{t}}\right)^{-\frac{1}{\psi}}\left(\frac{V_{t+1}\left(K_{t+1}, \hat{\mu}_{t+1}, A_{t+1}\right)}{\left[\hat{\mathbf{E}}_{t}\left(V_{t+1}^{1-\gamma}\left(K_{t+1}, \hat{\mu}_{t+1}, A_{t+1}\right)\right]^{\frac{1}{1-\gamma}}\right.}\right)^{\frac{1}{\psi}-\gamma}\right)\right] \\
& =-\log \left[\hat{\mathbf{E}}_{t}\left(\beta\left(\frac{\hat{C}_{t+1}}{\hat{C}_{t}}\right)^{-\frac{1}{\psi}}\left(\frac{\hat{V}_{t+1}\left(K_{t+1}, \hat{\mu}_{t+1}, A_{t+1}\right)}{\left[\hat{\mathbf{E}}_{t}\left(\hat{V}_{t+1}^{1-\gamma}\left(K_{t+1}, \hat{\mu}_{t+1}, A_{t+1}\right)\left(\frac{A_{t+1}}{A_{t}}\right)^{1-\gamma}\right)\right]^{\frac{1}{1-\gamma}}}\right)^{\frac{1}{\psi}-\gamma}\left(\frac{A_{t+1}}{A_{t}}\right)^{-\gamma}\right)\right] .
\end{aligned}
$$

Long-term bond prices can be calculated recursively by

$$
\begin{aligned}
P_{t, t+n} & =\hat{\mathbf{E}}_{t} M_{t, t+n} \\
& =\hat{\mathbf{E}}_{t}\left[M_{t, t+1} \hat{\mathbf{E}}_{t+1}\left(M_{t+1, t+n}\right)\right] \\
& =\hat{\mathbf{E}}_{t}\left[M_{t, t+1} P_{t+1, t+n}\right]
\end{aligned}
$$

From the long-term bond price, we can easily obtain the long-term bond yield. Lastly, to find Tobin's $Q$, let

$$
\frac{\hat{I}_{t}}{K_{t}} \equiv \phi\left(\frac{I_{t}}{K_{t}}\right) \text { and } \hat{\phi}\left(\hat{I}_{t}, K_{t}\right) \equiv I_{t}-\phi\left(\frac{I_{t}}{K_{t}}\right) K_{t}=I_{t}-\hat{I}_{t}
$$

Then, Tobin's $Q$ is

$$
\begin{aligned}
Q & =1+\frac{\partial \hat{\phi}\left(\hat{I}_{t}, K_{t}\right)}{\hat{I}_{t}}=\frac{\partial I_{t}}{\hat{I}_{t}}=\frac{\partial \phi^{-1}\left(\frac{\hat{I}_{t}}{K_{t}}\right)}{\frac{\hat{I}_{t}}{K_{t}}} \\
& =\frac{1}{\phi^{\prime}\left(\phi^{-1}\left(\frac{\hat{I}_{t}}{K_{t}}\right)\right)}=\frac{1}{\phi^{\prime}\left(\frac{I}{K}\right)} .
\end{aligned}
$$




\section{Table 1: Parameter Choices for Benchmark Calibration}

This table reports the parameter choices for the benchmark calibration. The model is simulated in quarterly frequency. These parameters are in quarterly frequency as well. The first five parameters are fixed for all of our calibration, whereas the last five parameters vary across calibrations.

\begin{tabular}{lccr}
\hline Statistics & Variable & B.I & B.II \\
\hline Fixed Parameter: & & & \\
& & & \\
Mean technology growth (\%) & $\mu_{A}$ & 0.4 & - \\
Volatility of the innovation in technology growth (\%) & $\sigma_{A}$ & 4.11 & - \\
Share of capital & $\alpha$ & 0.36 & - \\
Depreciation (\%) & $\delta_{K}$ & 0.21 & - \\
Leverage & $B / E$ & $2 / 3$ & - \\
& & & \\
Varying Parameter: & & & \\
& & & \\
Extrapolation parameter & $\rho$ & 0.98 & 0.95 \\
Risk aversion & $\gamma$ & 4.00 & 2.00 \\
IES & $\psi$ & 2.00 & - \\
Capital adjustment cost & $\xi$ & 1.50 & - \\
Subjective discount factor & $\beta$ & 0.991 & - \\
\hline
\end{tabular}




\section{Table 2: Moments for Quantities and Prices}

This table reports the results for eight calibrations. All the numbers are annualized. The mean and volatility are reported in percentages. $\Delta c_{t}$ denotes consumption growth; $\Delta y_{t}$ denotes output growth; $\Delta i_{t}$ denotes investment growth; $I K$ denotes investment over capital; $x_{t}$ denotes the perceived consumption growth by the agent in the model; $r_{f, t}$ denotes the risk-free rate; $r_{E, t}-r_{f, t}$ denotes the levered equity excess returns; $w-c$ denotes the log wealth-consumption ratio; $r_{w c}$ denotes the return on the aggregate consumption claim. The moments for asset prices in the data column are taken from Campbell and Cochrane (1999) and Bansal and Yaron (2004). We report a range of the values for these moments from these two papers based on different data samples. The moments for quantities are taken from Boldrin, Christiano, and Fisher (2001), Kaltenbrunner and Lochstoer (2010), and Kung (2012). Again, we report a range of values for these moments based on different data samples. The volatility of IK is taken from an old sample in Cochrane (1991) and is calculated from an updated sample from 1947Q1-2009Q4. Volatility of the aggregate Q is taken from Pontiff and Schall (1998). The expected term premium is taken from Jermann (1998) and Piazzesi and Schneider (2006). The range of moments for the wealth-consumption ratio and the log returns on aggregate wealth are taken from Lustig et al. (2008) based on both quarterly and annual data. 


\begin{tabular}{l|crrrrrrr} 
Parameter & Data & B.I & B.II & III & IV & V & VI & VII \\
\hline Risk Aversion $(\gamma)$ & NA & 4.00 & 2.00 & 4.00 & 4.00 & 4.00 & 4.00 & 2.00 \\
IES $(\psi)$ & NA & 2.00 & 2.00 & 2.00 & 2.00 & 2.00 & 3.00 & 2.00 \\
Time Discount $(\beta)$ & NA & 0.991 & 0.991 & 0.995 & 0.995 & 0.991 & 0.991 & 0.991 \\
Adjustment Cost $(\xi)$ & NA & 1.50 & 1.50 & 10.00 & 1.50 & 15.00 & 1.50 & 1.50 \\
Extrapolation $(\rho)$ & NA & 0.98 & 0.95 & 1.00 & 1.00 & 0.98 & 0.98 & 0.98 \\
\hline$\sigma\left(\Delta c_{t}\right)$ & $1.22-3.22$ & 3.78 & 2.41 & 2.46 & 4.51 & 1.53 & 3.28 & 3.63 \\
$\sigma\left(\Delta i_{t}\right)$ & $9.03-17.40$ & 9.09 & 12.72 & 11.42 & 6.85 & 14.33 & 10.37 & 9.33 \\
$\sigma\left(\Delta c_{t}\right) / \sigma\left(\Delta y_{t}\right)$ & $0.40-0.64$ & 0.72 & 0.46 & 0.47 & 0.86 & 0.29 & 0.62 & 0.69 \\
$\sigma\left(\Delta i_{t}\right) / \sigma\left(\Delta y_{t}\right)$ & $2.39-3.32$ & 1.73 & 2.42 & 2.17 & 1.30 & 2.72 & 1.97 & 1.78 \\
Adj. cost/output $(\%)$ & NA & 0.37 & 0.48 & 0.08 & 0.31 & 0.07 & 0.45 & 0.40 \\
$\sigma(I K)$ & $0.78-1.80$ & 0.92 & 1.06 & 1.00 & 0.74 & 1.14 & 1.02 & 0.94 \\
$\sigma(Q)$ & 0.23 & 0.12 & 0.14 & 0.02 & 0.10 & 0.02 & 0.13 & 0.12 \\
\hline$E\left(r_{f, t}\right)$ & $0.86-2.92$ & 1.29 & 0.87 & 2.20 & 1.89 & 2.25 & 0.83 & 2.41 \\
$\sigma\left(r_{f, t}\right)$ & 0.97 & 0.28 & 0.32 & 0.37 & 0.15 & 0.36 & 0.11 & 0.27 \\
$E\left(r_{E, t}-r_{f, t}\right)$ & $3.90-6.33$ & 5.42 & 5.48 & 0.78 & 1.44 & 0.79 & 6.04 & 2.93 \\
$\sigma\left(r_{E, t}-r_{f, t}\right)$ & $15.7-19.42$ & 10.37 & 14.46 & 2.14 & 7.85 & 1.83 & 11.78 & 10.64 \\
Sharpe Ratio & $0.22-0.43$ & 0.52 & 0.38 & 0.37 & 0.19 & 0.44 & 0.51 & 0.28 \\
\hline $\mathrm{E}(10$-year term premium) $)$ & $-2-1.7$ & -0.70 & -0.92 & -0.36 & -0.17 & -0.98 & -0.31 & -0.40 \\
$\sigma(10$-year term premium $)$ & NA & 0.07 & 0.10 & 0.20 & 0.05 & 0.13 & 0.03 & 0.07 \\
\hline$\sigma(w-c)$ & $22.21-34.48$ & 12.42 & 19.97 & 4.56 & 3.26 & 13.24 & 16.36 & 17.11 \\
$\sigma\left(r_{w c}\right)$ & $9.88-12.44$ & 9.57 & 15.24 & 4.91 & 6.01 & 7.94 & 10.96 & 11.60 \\
$E(w-c)$ & $4.47-5.02$ & 4.50 & 4.55 & 5.39 & 5.39 & 4.54 & 4.48 & 4.74 \\
$E\left(r_{w c}\right)$ & $1.72-2.16$ & 4.79 & 5.06 & 1.25 & 1.56 & 3.66 & 5.37 & 2.77 \\
$\sigma\left(x_{t}\right)$ & NA & 0.79 & 1.12 & 0.72 & 0.33 & 0.99 & 0.83 & 0.80 \\
$\sigma\left(x_{t}\right) / \sigma\left(\Delta c_{t}\right)$ & NA & 0.21 & 0.49 & 0.29 & 0.07 & 0.65 & 0.25 & 0.22 \\
$A C\left(x_{t}\right)$ & NA & 0.87 & 0.79 & 0.83 & 0.88 & 0.82 & 0.87 & 0.87 \\
\hline & & & & & & & &
\end{tabular}


Table 3: Long Horizon Stock Return Predictability by DP Ratio, IK, and Tobin's $\mathrm{Q}$

We regress cumulative 1-, 3-, and 5-year excess stock market returns on the dividend-price ratio, investment over capital, and Tobin's Q. We report results on both coefficients and $R^{2} \mathrm{~s}$. We simulate the model for 400 quarters and repeat the procedure 1,000 times to obtain small sample values. The median (50\%) values and the $95 \%$ confidence intervals are reported.

Panel A: Benchmark Calibration I: $\rho=0.98$

\begin{tabular}{|c|c|c|c|c|c|c|c|c|c|c|}
\hline \multirow[b]{2}{*}{ horizon } & \multirow[b]{2}{*}{ statistics } & \multicolumn{3}{|c|}{ DP } & \multicolumn{3}{|c|}{ IK } & \multicolumn{3}{|c|}{ Q } \\
\hline & & $50 \%$ & $2.5 \%$ & $97.5 \%$ & $50 \%$ & $2.5 \%$ & $97.5 \%$ & $50 \%$ & $2.5 \%$ & $97.5 \%$ \\
\hline \multirow[t]{2}{*}{1} & coef & 3.01 & 0.90 & 7.58 & -1.36 & -3.63 & -0.37 & -0.05 & -0.13 & -0.01 \\
\hline & R-sqr & 2.11 & 0.40 & 6.01 & 1.95 & 0.29 & 5.90 & 1.98 & 0.30 & 5.90 \\
\hline \multirow[t]{2}{*}{3} & coef & 5.88 & 1.74 & 14.77 & -2.66 & -7.03 & -0.71 & -0.10 & -0.26 & -0.03 \\
\hline & R-sqr & 4.19 & 0.74 & 11.88 & 3.90 & 0.54 & 11.56 & 3.91 & 0.54 & 11.54 \\
\hline \multirow[t]{2}{*}{5} & coef & 8.75 & 2.48 & 22.09 & -3.93 & -10.48 & -0.95 & -0.15 & -0.39 & -0.04 \\
\hline & R-sqr & 6.21 & 1.03 & 18.07 & 5.73 & 0.78 & 17.72 & 5.72 & 0.81 & 17.77 \\
\hline
\end{tabular}

Panel B: Benchmark Calibration II: $\rho=0.95$

\begin{tabular}{|c|c|c|c|c|c|c|c|c|c|c|}
\hline \multirow[b]{2}{*}{ horizon } & \multirow[b]{2}{*}{ statistics } & \multicolumn{3}{|c|}{$\mathrm{DP}$} & \multicolumn{3}{|c|}{ IK } & \multicolumn{3}{|c|}{$\mathrm{Q}$} \\
\hline & & $50 \%$ & $2.5 \%$ & $97.5 \%$ & $50 \%$ & $2.5 \%$ & $97.5 \%$ & $50 \%$ & $2.5 \%$ & $97.5 \%$ \\
\hline \multirow[t]{2}{*}{1} & coef & 3.93 & 1.80 & 7.42 & -2.39 & -4.84 & -1.08 & -0.09 & -0.18 & -0.04 \\
\hline & R-sqr & 4.34 & 1.69 & 8.76 & 4.35 & 1.69 & 9.04 & 4.38 & 1.74 & 9.01 \\
\hline \multirow[t]{2}{*}{3} & coef & 7.48 & 3.49 & 14.23 & -4.66 & -9.33 & -2.05 & -0.18 & -0.35 & -0.08 \\
\hline & R-sqr & 8.33 & 3.17 & 16.40 & 8.40 & 3.13 & 17.09 & 8.46 & 3.22 & 17.04 \\
\hline \multirow[t]{2}{*}{5} & coef & 10.78 & 4.83 & 20.87 & -6.56 & -13.33 & -2.94 & -0.25 & -0.51 & -0.11 \\
\hline & $\mathrm{R}$-sqr & 11.93 & 4.40 & 24.65 & 12.13 & 4.52 & 24.77 & 12.21 & 4.46 & 24.77 \\
\hline
\end{tabular}

Panel C: Calibration III: $\rho=1$

\begin{tabular}{|c|c|c|c|c|c|c|c|c|c|c|}
\hline \multirow[b]{2}{*}{ horizon } & \multirow[b]{2}{*}{ statistics } & \multicolumn{3}{|c|}{$\mathrm{DP}$} & \multicolumn{3}{|c|}{ IK } & \multicolumn{3}{|c|}{$\mathrm{Q}$} \\
\hline & & $50 \%$ & $2.5 \%$ & $97.5 \%$ & $50 \%$ & $2.5 \%$ & $97.5 \%$ & $50 \%$ & $2.5 \%$ & $97.5 \%$ \\
\hline \multirow[t]{2}{*}{1} & coef & 0.22 & -0.23 & 0.99 & -0.11 & -0.49 & 0.11 & -0.03 & -0.12 & 0.03 \\
\hline & R-sqr & 0.43 & 0.00 & 3.64 & 0.43 & 0.00 & 3.64 & 0.43 & 0.00 & 3.62 \\
\hline \multirow[t]{2}{*}{3} & coef & 0.45 & -0.43 & 1.90 & -0.22 & -0.95 & 0.21 & -0.05 & -0.24 & 0.05 \\
\hline & R-sqr & 0.87 & 0.00 & 7.00 & 0.86 & 0.00 & 7.00 & 0.88 & 0.00 & 7.14 \\
\hline \multirow[t]{2}{*}{5} & coef & 0.68 & -0.68 & 2.99 & -0.33 & -1.49 & 0.34 & -0.08 & -0.36 & 0.08 \\
\hline & R-sqr & 1.36 & 0.00 & 11.10 & 1.34 & 0.00 & 11.06 & 1.34 & 0.00 & 11.24 \\
\hline
\end{tabular}




\section{Table 4: Consumption Dynamics}

We report the 1st, 4th, 8th, 12th, 16th, and 20th order autocorrelations of consumption growth for different versions of calibration. We simulate the model for 400 quarters and repeat 1,000 times to obtain small sample values. The median (50\%) values and the $95 \%$ confidence intervals are reported. Quarterly seasonally adjusted consumption data are obtained from Bureau of Economic Analysis, 1947Q1-2009Q4.

Panel A: Benchmark Calibration I: $\rho=0.98$

\begin{tabular}{lcccc}
\hline horizon & $50 \%$ & $2.5 \%$ & $97.5 \%$ & Data \\
\hline 1 & 0.04 & -0.06 & 0.15 & 0.26 \\
4 & 0.03 & -0.06 & 0.14 & 0.15 \\
8 & 0.03 & -0.07 & 0.14 & -0.03 \\
12 & 0.03 & -0.08 & 0.13 & 0.03 \\
16 & 0.02 & -0.08 & 0.13 & 0.07 \\
20 & 0.02 & -0.08 & 0.13 & -0.04 \\
\hline
\end{tabular}

Panel B: Benchmark Calibration II: $\rho=0.95$

\begin{tabular}{lcccc}
\hline horizon & $50 \%$ & $2.5 \%$ & $97.5 \%$ & Data \\
\hline 1 & 0.20 & 0.06 & 0.36 & 0.26 \\
4 & 0.16 & 0.03 & 0.33 & 0.15 \\
8 & 0.14 & 0.01 & 0.28 & -0.03 \\
12 & 0.10 & -0.02 & 0.27 & 0.03 \\
16 & 0.08 & -0.04 & 0.24 & 0.07 \\
20 & 0.06 & -0.06 & 0.23 & -0.04 \\
\hline
\end{tabular}

Panel C: Calibration III: $\rho=1$ and $\xi=10$

\begin{tabular}{lcccc}
\hline horizon & $50 \%$ & $2.5 \%$ & $97.5 \%$ & Data \\
\hline 1 & 0.14 & 0.01 & 0.29 & 0.26 \\
4 & 0.13 & 0.01 & 0.28 & 0.15 \\
8 & 0.11 & -0.02 & 0.25 & -0.03 \\
12 & 0.09 & -0.04 & 0.25 & 0.03 \\
16 & 0.07 & -0.05 & 0.22 & 0.07 \\
20 & 0.06 & -0.06 & 0.21 & -0.04 \\
\hline
\end{tabular}

Panel D: Calibration IV: $\rho=1$ and $\xi=1.5$

\begin{tabular}{lcccc}
\hline horizon & $50 \%$ & $2.5 \%$ & $97.5 \%$ & Data \\
\hline 1 & 0.02 & -0.08 & 0.12 & 0.26 \\
4 & 0.01 & -0.08 & 0.11 & 0.15 \\
8 & 0.01 & -0.08 & 0.12 & -0.03 \\
12 & 0.01 & -0.09 & 0.11 & 0.03 \\
16 & 0.01 & -0.09 & 0.11 & 0.07 \\
20 & 0.01 & -0.08 & 0.11 & -0.04 \\
\hline
\end{tabular}




\section{Table 5: Return Predictability by Perceived Growth}

This table reports the long-horizon predictive regressions of market excess returns onto the negative output gap (NGAP) of Cooper and Priestley (2009) and $\hat{\mu}$ calculated from exponentially weighted moving average of both realized GDP growth rates and TFP growth from BLS with exponential decay parameter $\tilde{\rho}=0.95$. We report t-statistics calculated from Newey and West (1987) standard errors (t(NW)), Hansen and Hodrick (1980) standard errors $(\mathrm{t}(\mathrm{HH}))$, and Hodrick (1992) standard errors ( $\mathrm{t}(\mathrm{HD})$ ). The data sample for all raw series is 1947Q2-2009Q4. The resulting data sample for $\hat{\mu}_{t}$ is 1957Q1-2009Q4.

\begin{tabular}{crrrrr}
\multicolumn{6}{c}{$\hat{\mu}_{A}$ from GDP Growth Predicts Returns } \\
\hline Horizon & coef. & $\mathrm{t}(\mathrm{NW})$ & $\mathrm{t}(\mathrm{HH})$ & $\mathrm{t}(\mathrm{HD})$ & $\mathrm{R}^{2}$ \\
\hline 1-quar & -7.73 & -2.08 & -1.90 & -2.25 & 0.02 \\
1-year & -23.08 & -1.71 & -1.52 & -1.64 & 0.04 \\
2-year & -38.45 & -1.91 & -1.79 & -1.42 & 0.06 \\
3-year & -67.70 & -3.35 & -3.03 & -1.83 & 0.16 \\
4-year & -92.32 & -4.46 & -3.62 & -1.98 & 0.26 \\
5-year & -111.68 & -4.52 & -4.01 & -1.98 & 0.31 \\
\hline
\end{tabular}

$\hat{\mu}_{A}$ from TFP Growth Predicts Returns

\begin{tabular}{rrrrrr}
\hline Horizon & coef. & $\mathrm{t}(\mathrm{NW})$ & $\mathrm{t}(\mathrm{HH})$ & $\mathrm{t}(\mathrm{HD})$ & $\mathrm{R}^{2}$ \\
\hline 1-quar & -4.45 & -1.42 & -1.30 & -1.47 & 0.01 \\
1-year & -13.84 & -1.38 & -1.30 & -1.23 & 0.02 \\
2-year & -18.69 & -1.26 & -1.15 & -0.89 & 0.02 \\
3-year & -31.77 & -1.91 & -1.63 & -1.04 & 0.05 \\
4-year & -46.13 & -2.21 & -1.89 & -1.15 & 0.08 \\
5-year & -61.07 & -2.39 & -1.95 & -1.20 & 0.12 \\
\hline
\end{tabular}

NGAP Predicts Returns

\begin{tabular}{rrrrrr}
\hline Horizon & coef. & $\mathrm{t}(\mathrm{NW})$ & $\mathrm{t}(\mathrm{HH})$ & $\mathrm{t}(\mathrm{HD})$ & $\mathrm{R}^{2}$ \\
\hline 1-quar & 0.28 & 4.03 & 3.73 & 3.62 & 0.05 \\
1-year & 0.89 & 3.28 & 2.95 & 2.84 & 0.12 \\
2-year & 1.30 & 3.10 & 3.17 & 2.17 & 0.14 \\
3-year & 1.80 & 4.36 & 4.67 & 2.16 & 0.22 \\
4-year & 2.31 & 5.23 & 4.59 & 2.22 & 0.33 \\
5-year & 2.81 & 5.34 & 4.40 & 2.24 & 0.39 \\
\hline
\end{tabular}




\section{Table 6: Predictability of GDP Growth and TFP Growth}

This table reports the long-horizon predictive regressions of GDP growth and TFP growth onto the negative output gap (NGAP) of Cooper and Priestley (2009) and $\hat{\mu}$ calculated from an exponentially weighted moving average of realized GDP growth rates with exponential decay parameter $\tilde{\rho}=0.95$. We report t-statistics calculated from Newey and West (1987) standard errors (t(NW)), Hansen and Hodrick (1980) standard errors $(\mathrm{t}(\mathrm{HH}))$, and Hodrick (1992) standard errors (t(HD)). The data sample for all raw series is 1947Q2-2009Q4. The resulting data sample for $\hat{\mu}_{t}$ is 1957Q1-2009Q4.

NGAP Predicts GDP Growth

\begin{tabular}{rrrrrr}
\hline Horizon & coef. & $\mathrm{t}(\mathrm{NW})$ & $\mathrm{t}(\mathrm{HH})$ & $\mathrm{t}(\mathrm{HD})$ & $\mathrm{R}^{2}$ \\
\hline 1-quar & 0.01 & 0.79 & 0.78 & 1.00 & 0.00 \\
1-year & 0.20 & 3.18 & 2.88 & 3.78 & 0.12 \\
2-year & 0.40 & 3.63 & 3.23 & 4.49 & 0.21 \\
3-year & 0.51 & 3.58 & 3.15 & 4.42 & 0.24 \\
4-year & 0.57 & 3.41 & 3.00 & 4.24 & 0.25 \\
5-year & 0.63 & 3.55 & 3.29 & 3.95 & 0.25 \\
\hline
\end{tabular}

$\hat{\mu}_{A}$ from GDP Predicts GDP growth

\begin{tabular}{rrrrr}
\hline coef. & $\mathrm{t}(\mathrm{NW})$ & $\mathrm{t}(\mathrm{HH})$ & $\mathrm{t}(\mathrm{HD})$ & $\mathrm{R}^{2}$ \\
\hline 0.52 & 0.95 & 0.94 & 1.26 & 0.01 \\
-0.61 & -0.25 & -0.22 & -0.36 & 0.00 \\
-4.18 & -1.02 & -0.91 & -1.31 & 0.03 \\
-6.77 & -1.39 & -1.22 & -1.60 & 0.06 \\
-8.80 & -1.69 & -1.46 & -1.72 & 0.08 \\
-9.17 & -1.90 & -1.72 & -1.55 & 0.08 \\
\hline
\end{tabular}

NGAP Predicts TFP Growth

\begin{tabular}{rrrrrrrrrrrrr}
\hline Horizon & coef. & $\mathrm{t}(\mathrm{NW})$ & $\mathrm{t}(\mathrm{HH})$ & $\mathrm{t}(\mathrm{HD})$ & $\mathrm{R}^{2}$ & & & coef. & $\mathrm{t}(\mathrm{NW})$ & $\mathrm{t}(\mathrm{HH})$ & $\mathrm{t}(\mathrm{HD})$ & $\mathrm{R}^{2}$ \\
\hline 1-quar & 0.03 & 2.80 & 2.76 & 2.81 & 0.03 & & -0.98 & -2.06 & -1.97 & -2.37 & 0.03 \\
1-year & 0.14 & 3.98 & 3.60 & 3.73 & 0.19 & & -4.09 & -2.35 & -2.12 & -2.37 & 0.09 \\
2-year & 0.18 & 3.24 & 2.90 & 2.86 & 0.18 & & -5.94 & -2.29 & -2.11 & -1.90 & 0.10 \\
3-year & 0.20 & 2.44 & 2.13 & 2.25 & 0.14 & & -6.83 & -2.55 & -2.43 & -1.59 & 0.09 \\
4-year & 0.19 & 1.82 & 1.59 & 1.81 & 0.11 & & -6.75 & -2.30 & -2.36 & -1.29 & 0.07 \\
5-year & 0.20 & 1.66 & 1.43 & 1.58 & 0.10 & & -6.02 & -2.00 & -2.02 & -0.97 & 0.05 \\
\hline
\end{tabular}


Table 7: Predictability of Investment Rates by Perceived Growth and Cash Flow

This table reports the predictive regressions of the investment rate, I/K, onto cash flow (corporate profits to capital ratio) and perceived growth calculated from an exponentially weighted moving average of realized GDP and TFP growth rates with exponential decay parameter $\tilde{\rho}=0.95$. The data sample for all raw series is 1947Q2-2009Q4. The resulting data sample for $\hat{\mu}_{t}$ is 1957Q1-2009Q4. Newey and West (1987) standard errors with lag of 4 is used to calculate the t-statistics, which is in parenthesis.

\begin{tabular}{rcccc} 
& I & II & III & IV \\
\hline$\hat{\mu}_{A}$ from GDP & & 1.81 & 1.86 & \\
& & $(9.65)$ & $(10.34)$ & \\
$\hat{\mu}_{A}$ from TPF & & & & 1.48 \\
& & & & $(5.00)$ \\
Cash Flow & 0.17 & 0.01 & & \\
& $(6.43)$ & $(0.50)$ & & \\
R-sqr & 0.30 & 0.66 & 0.66 & 0.29 \\
\hline
\end{tabular}




\section{Figure 1: Evolution of I/K and the Perceived Growth Rate}

The top figure plots the evolution of IK and the perceived growth rate. The bottom figure plots the evolution of change in $I / K$ from $t-4$ to $t$ and the change in the perceived growth rate from $t-4$ to $t . I / K$ is nonresidential fixed investment divided by the replacement cost. The perceived growth rate is calculated as the exponentially weighted moving average of realized GDP growth rates with exponential decay parameter $\tilde{\rho}=0.95$. All data are from NIPA. The data sample for all raw series is 1947Q2-2009Q4. The resulting data sample for $\hat{\mu}_{A}$ is 1957Q1-2009Q4.
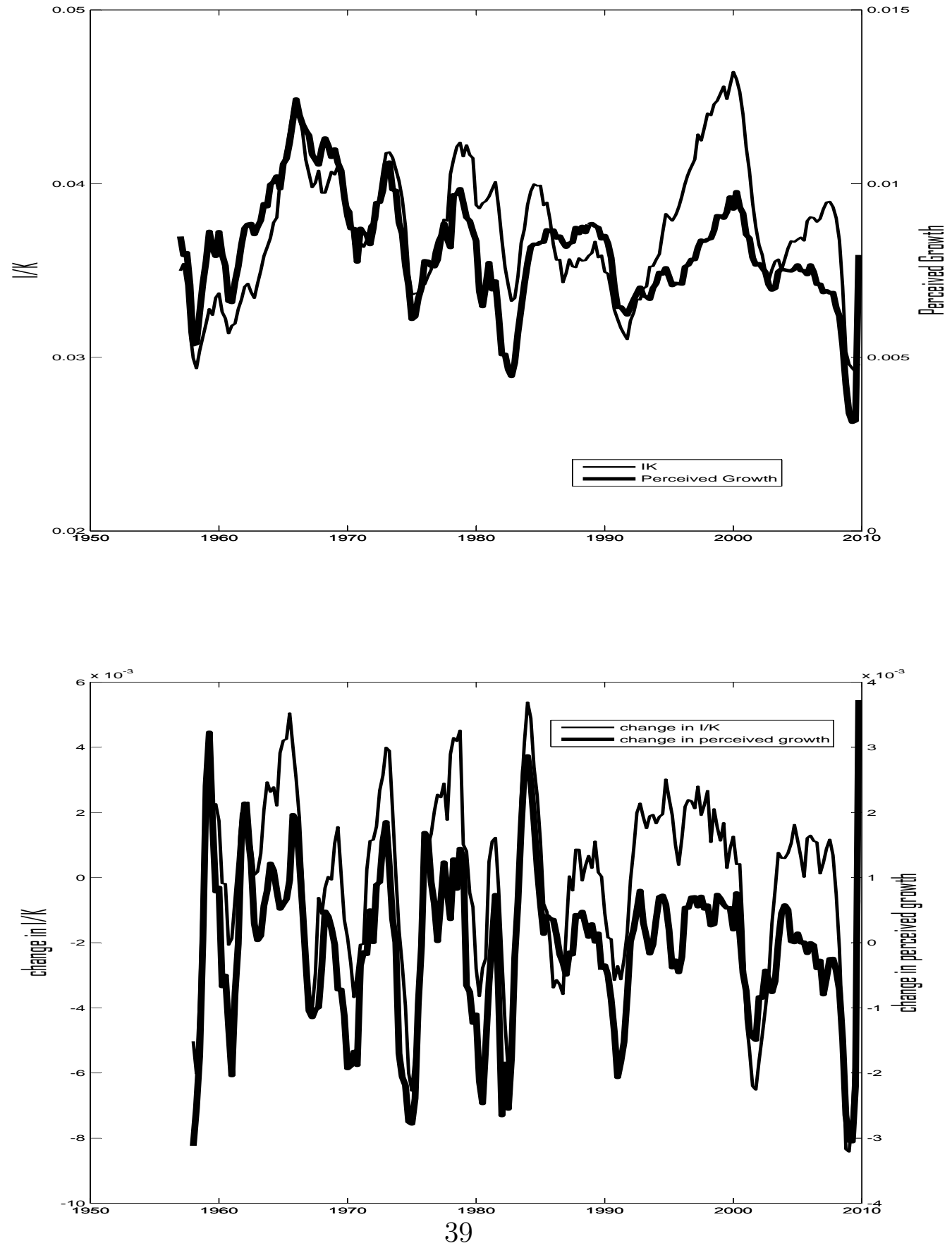


\section{References}

Abel, Andrew B., 1999, Risk premia and term premia in general equilibrium, Journal of Monetary Economics 43, 3-33.

Ai, Hengjie, 2010, Information quality and long-run risk: asset pricing implications, Journal of Finance 65, 1333-1367.

Ang, Andrew, and Geert Bekaert. 2007. Stock return predictability: Is it there? Review of Financial Studies 20, 651-707.

Attanasio, Orazio P. and Annette Vissing-Jorgensen, 2003, Stock-market participation, intertemporal substitution and risk aversion, American Economic Review Papers and Proceedings 93, 383-391.

Barlevy, Gadi, 2004, The cost of business cycles under endogenous growth, American Economic Review 94, 964-990.

Bansal, Ravi, and Amir Yaron, 2004, Risks for the long run: A potential resolution of asset pricing puzzles, Journal of Finance 59, 1481-1509.

Bansal, Ravi, Ronald Gallant, and George Tauchen, 2007, Rational pessimism and exuberance, Review of Economic Studies 74, 1005-1033.

Bansal, Ravi, Dana Kiku, and Amir Yaron, 2007, Risks for the long run: Estimation and inference, Working Paper, Duke University and University of Pennsylvania.

Bansal, Ravi, Dana Kiku, and Amir Yaron, 2012, An empirical evaluation of the long-run risks model for asset prices, Critical Finance Review 1, 183-221.

Barberis, Nicholas, 2011, Psychology and the Financial Crisis of 2007-2008, Financial Innovation and Crisis, M. Haliassos ed.

Barberis, Nicholas and Richard Thaler, 2003, A Survey of Behavioral Finance, Handbook of the Economics of Finance, G. Constantinides, R. Stulz, M. Harris eds., North Holland, Amsterdam.

Barro, Robert J., 2006, Rare disasters and asset markets in the twentieth century, Quarterly Journal of Economics 121, 823-866. 
Barsky, Robert, and Bradford J. De Long, 1993, Why does the stock market fluctuate? Quarterly Journal of Economics 108, 291-312.

Beaudry, Paul and Franck Portier, 2006, Stock prices, news, and economic fluctuations, American Economic Review 96, 1293-1307.

Benninga, Simon and Aris Protopapadakis, 1990, Leverage, time preference and the equity premium puzzle, Journal of Monetary Economics 25, 49-58.

Van Binsbergen, Jules, Jesus Fernandez-Villaverde, Ralph S.J. Koijen, and Juan F. RubioRamirez, 2011, The term structure of interest rates in a DSGE model with recursive preferences, Working Paper, Stanford University.

Benartzi, Shlomo, 2001, Excessive Extrapolation and the Allocation of 401(k) accounts to company stock, Journal of Finance 56, 1747-1764.

Boldrin, Michele, Lawrence J. Christiano, and Jonas D. M. Fisher, 2001, Habit persistence, asset returns, and the business cycle, American Economic Review 91, 149-166.

Boldrin, Michele, Lawrence J. Christiano, and Jonas D. M. Fisher, 1995, Asset pricing lessons for modeling business cycles, NBER Working Paper 5262.

Brandt, Michael, Qi Zeng, and Lu Zhang, 2004, Equilibrium stock return dynamics under alternative rules of learning about hidden states, Journal of Economic Dynamics and Control 28, 1925-1954.

Brennan, Michael J., and Yihong Xia, 2001, Stock price volatility and equity premium, Journal of Monetary Economics 47, 249-283.

Campanale, Claudio, Rui Castro, and Gian Luca Clementi, 2010, Asset pricing in a production economy with Chew-Dekel preferences, Review of Economic Dynamics 13, 379-402.

Campbell, John Y., 1994, Inspecting the mechanism: An analytical approach to the stochastic growth model, Journal of Monetary Economics 33, 463-506.

Campbell, John Y., 2003, Consumption-based asset pricing, Handbook of the Economics of Finance, Edited by G.M. Constantinides, M. Harris and R. Stulz, 801-885.

Campbell, John Y. and John H. Cochrane, 1999, By force of habit: A consumption-based 
explanation of aggregate stock market behavior, Journal of Political Economy 107, 205251.

Campbell, John Y. and N. Gregory Mankiw, 1989, Consumption, income, and interest rates: Reinterpreting the time series evidence, in O.J. Blanchard and S. Fischer eds., NBER Macroeconomics Annual 4, 185-216.

Campbell, John Y., and Robert J. Shiller, 1988, Stock prices, earnings, and expected dividends, Journal of Finance 43, 661-676.

Campbell, John Y. and Robert J. Shiller, 1988, The dividend-price ratio and expectations of future dividends and discount factors, Review of Financial Studies 1, 195-228.

Campbell, J., Thompson, S., 2008. Predicting excess stock returns out of sample: Can anything beat the historical average? Review of Financial Studies 21, 1509-1531.

Campbell, Sean, and Francis Diebold, 2009, Stock returns and expected business conditions: Half a century of direct evidence, Journal of Business and Economic Statistics 27, 266278.

Carceles-Poveda, Eva and Chryssi Giannitsarou, 2008, Asset pricing with adaptive learning, Review of Economic Dynamics 11, 629-651.

Case, Karl, and Robert Shiller, 1988, The behavior of home buyers in boom and post boom markets, in R. Shiller, 1989, Market Volatility, Cambridge, MA: MIT Press.

Cecchetti, Stephen, Pok-Sang Lam, and Nelson Mark, 2000, Asset pricing with distorted beliefs: Are equity returns too good to be true? American Economic Review 90, 787805.

Choi, James, 2006, Extrapolative expectations and the equity premium, Working Paper, Yale University.

Choi, James, David Laibson, and Brigitte Madrian, 2010, Why Does the Law of One Price Fail? An Experiment on Index Mutual Funds, Review of Financial Studies 23, 1405-1432.

Cochrane, John, 1991, Production-based asset pricing and the link between stock returns and economic fluctuations, Journal of Finance 46, 209-237.

Cochrane, John, 2008. The dog that did not bark: A defense of return predictability. Review 
of Financial Studies 21, 1533-1575.

Collin-Dufresne, Pierre, Michael Johannes, and Lars A. Lochstoer, 2012, Parameter learning in general equilibrium: The asset pricing implications, Working Paper, Columbia GSB.

Cooper, Ilan, and Richard Priestley, 2009, Time-varying risk premiums and the output gap, Review of Financial Studies 22, 2801-2833.

Croce, Mariano, 2010, Long-run productivity risk: A new hope for production-based asset pricing? Working Paper, University of North Carolina.

Daniel, Kent and Sheridan Titman, 2006, Market Reactions to Tangible and Intangible Information, Journal of Finance 61, 1605-1643.

De Bondt, Werner, 1993, Betting on trends: intuitive forecasts of financial risk and return, International Journal of Forecasting 9, 355-371.

De Bondt, Werner, and Richard Thaler, 1985, Does the stock market overreact? Journal of Finance 40, 793-805.

De Long, Bradford, Andrei Shleifer, Lawrence H. Summers, and Robert Waldmann, 1990a, Noise trader risk in financial markets, Journal of Political Economy 98, 703-738.

De Long, Bradford, Andrei Shleifer, Lawrence H. Summers, and Robert Waldmann, 1990b, Positive feedback investment strategies and destabilizing rational speculation, Journal of Finance 45, 379-395.

Durell, Alan, 1999, Consumer confidence and stock market returns, Working Paper, Harvard University.

Edge, Rochelle M., Thomas Laubach, and John C. Williams, 2007, Learning and shifts in long-run productivity growth, Journal of Monetary Economics 54, 2421-2438.

Ederington, Louis and Evgenia Golubeva, 2010, The impact of risk and return perceptions on the portfolio reallocation decisions of mutual fund investors, Working paper, University of Oklahoma.

Epstein, Larry G., and Stanley E. Zin, 1989, Substitution, risk aversion, and the intertemporal behavior of consumption and asset returns: A theoretical framework, Econometrica 57, 937-969. 
Fama, Eugene, and Kenneth French, 1988, Dividend yields and expected stock returns, Journal of Financial Economics 22, 3-25.

Fuster, Andreas, Benjamin Hebert, and David Laibson, 2011, Natural Expectations, Macroeconomic Dynamics, and Asset Pricing, NBER Macroeconomics Annual, Forthcoming.

Fuster, Andreas, David Laibson, and Brock Mendel, 2010, Natural expectations and macroeconomic fluctuations, Journal of Economic Perspectives 24, 67-84.

Goetzmann, William, Akiko Watanabe, and Masahiro Watanabe, 2010, Procyclical stock earn higher returns, Working paper, Yale University.

Goyal, Amit, and Ivo Welch, 2008, A comprehensive look at the empirical performance of equity premium prediction, Review of Financial Studies 21, 1455-1508.

Greenwood, Robin and Stefan Nagel, 2009, Inexperienced investors and bubbles, Journal of Financial Economics 93, 239-258.

Guvenen, Fatih, 2006, Reconciling conflicting evidence on the elasticity of intertemporal substitution: A macroeconomic perspective, Journal of Monetary Economics 53, 14511472 .

Hall, Robert E., 1988, Intertemporal substitution in consumption, Journal of Political Economy 96, 221-273.

Hansen, Lars, and Robert Hodrick, 1980, Forward exchange rates as optimal predictors of future spot rates: An econometric analysis, Journal of Political Economy 88, 829-853.

Haruvy, Ernan, Yaron Lahav, and Charles N. Noussair, 2007, Traders' Expectations in Asset Markets: Experimental Evidence, American Economic Review 97, 1901-1920.

Hassett, Kevin, and Glenn Hubbard, 1997, Tax policy and investment, Fiscal Policy: Lessons from the Literature, A. Auerbach, ed. Cambridge, MA: MIT Press.

Hirshleifer, David, 2001, Investor psychology and asset pricing, Journal of Finance 56, 15331597.

Hodrick, Robert, 1992, Dividend yields and expected stock returns: Alternative procedures for inference and measurement, Review of Financial Studies 5, 357-386. 
Hung, Howard, 2011, Equilibrium growth, inflation, and bond yields, Working paper, Duke University.

Imrohoroglu, Ayse, and and Selale Tuzel, 2011, Firm Level Productivity, Risk, and Return, Working paper, University of Southern California.

Jermann, Urban, 1998, Asset pricing in production economies, Journal of Monetary Economics 41, 257-275.

Kaltenbrunner, Georg, and Lars Lochstoer, 2010, Long-run risk through consumption smoothing, Review of Financial Studies 23, 3141-3189.

Kothari, S.P., and Jay Shanken, 1997, Book-to-market, dividend yield, and expected market returns: a time-series analysis, Journal of Financial Economics 44, 169-203.

Kydland, Finn E., and Edward C. Prescott, 1982, Time to build and aggregate fluctuations, Econometrica 50, 1345-1370.

Lakonishok, Josef, Shleifer, Andrei, and Robert W. Vishny, 1994, Contrarian investment, extrapolation, and risk, Journal of Finance 49, 1541-1578.

Lansing, Kevin, 2006, Lock-in of extrapolative expectations in an asset pricing model, Macroeconomic Dynamics 10, 317-348.

Lansing, Kevin, 2011, Speculative growth, overreaction, and the welfare cost of technologydriven bubbles, Working Paper, Federal Reserve Bank of San Francisco.

La Porta, Rafael, 1996. Expectations and the cross-section of returns. Journal of Finance 51, 1715-1742.

La Porta, Rafael, Lakonishok, Josef, Shleifer, Andrei, and Robert W. Vishny, 1997, Good news for value stocks: further evidence on market efficiency, Journal of Finance 52, 859-874.

Lettau, Martin, and Harald Uhlig, 2000, Can habit formation be reconciled with business cycle facts? Review of Economic Dynamics 3, 79-99.

Lustig, Hanno, Stijn Van Nieuwerburgh, and Adrien Verdelhan, 2008, The wealthconsumption ratio, Working Paper, UCLA, New York University, and Massachusetts Institute of Technology. 
Malmendier, Ulrike and Stefan Nagel, 2011, Learning from inflation experiences, Working Paper, UC Berkeley and Stanford.

Mehra, Rajnish, and Edward C. Prescott, 1985, The equity premium: A puzzle, Journal of Monetary Economics 15, 145-162.

Merton, Robert C., 1980, On estimating the expected return on the market: An exploratory investigation, Journal of Financial Economics 8, 1-39.

Newey, Whitney, and Kenneth West, 1987, A simple, positive semi-definite, heteroskedasticity and autocorrelation consistent covariance matrix, Econometrica 55, 703-708.

Orphanides, Athanasios and John Williams, 2005, The decline of activist stabilization policy: Natural rate misperceptions, learning, and expectations, Journal of Economic Dynamics and Control 29, 1927-1950.

Philippon, Thomas, 2009, The bond market's q, Quarterly Journal of Economics 124, 10111056.

Piazzesi, Monika, and Mark Schneider, 2006, Equilibrium yield curves, NBER Macroeconomics Annual, Cambridge MA: MIT Press, pp. 389-442.

Pontiff, Jeffrey, and Lawrence D. Schall, 1998, Book-to-market ratios as predictors of market returns, Journal of Financial Economics 49, 141-160

Poterba, James M., and Lawrence H. Summers, 1988, Mean-reversion in stock prices: evidence and implications, Journal of Financial Economics 22, 27-59.

Rapach, David, Jack Strauss, and Guofu Zhou, 2010, Out-of-Sample Equity Premium Prediction: Combination Forecasts and Links to the Real Economy, Review of Financial Studies 23, 821-862.

Restoy, Fernando and Michael Rockinger, 1994, On stock market returns and returns on investment, Journal of Finance 49, 543-555.

Rouwenhorst, Geert, 1995, Asset pricing implications of equilibrium business cycle models. In T. F. Cooley (Ed.), Frontiers of Business Cycle Research, Chapter 10, pp. 294-330. Princeton, NJ: Princeton University Press. 
Sargent, Thomas, 1993, Bounded Rationality in Macroeconomics, Oxford, UK, Clarendon Press.

Smith, Vernon L. and Gerry L. Suchanek, and Arlington W. Williams, 1988, Bubbles, crashes and endogenous expectations in experimental spot asset markets, Econometrica 56, 11191151.

Tallarini, Thomas, 2000, Risk-sensitive real business cycles, Journal of Monetary Economics $45,507-532$.

Tversky, Amos, and Daniel Kahneman, 1974, Judgment under uncertainty: heuristics and biases, Science 185, 1124-1131.

Timmerman, Allan, 1993, How learning in financial markets generates excess volatility and predictability in stock prices, Quarterly Journal of Economics 108, 1135-1145.

Timmerman, Allan, 1996, Excess volatility and predictability of stock prices in autoregressive dividend models with learning, Review of Economic Studies 63, 523-557.

Vissing-Jorgensen, Annette, 2002, Limited asset market participation and the elasticity of intertemporal substitution, Journal of Political Economy 110, 825-853.

Vissing-Jorgensen, Annette, 2003, Perspectives on behavioral finance: Does "irrationality" disappear with wealth? Evidence from expectations and actions, NBER Macroeconomics Annual 18, 139-194.

Weil, Philippe, 1989, The equity premium puzzle and the risk-free rate puzzle, Journal of Monetary Economics 24, 401-421. 